This item was submitted to Loughborough's Research Repository by the author.

Items in Figshare are protected by copyright, with all rights reserved, unless otherwise indicated.

\title{
Differentiation of bioengineered skeletal muscle within a 3D printed perfusion bioreactor reduces atrophic and inflammatory gene expression
}

\section{PLEASE CITE THE PUBLISHED VERSION}

\section{PUBLISHER}

American Chemical Society (ACS)

\section{VERSION}

AM (Accepted Manuscript)

\section{PUBLISHER STATEMENT}

This document is the Accepted Manuscript version of a Published Work that appeared in final form in ACS Biomaterials Science \& Engineering, copyright () American Chemical Society after peer review and technical editing by the publisher. To access the final edited and published work see https://pubs.acs.org/doi/10.1021/acsbiomaterials.9b00975.

\section{LICENCE}

CC BY-NC-ND 4.0

\section{REPOSITORY RECORD}

Rimington, Rowan, Andrew Capel, Kerry Chaplin, Jacob Fleming, Hemaka Bandulasena, Richard Bibb, Steven Christie, and Mark Lewis. 2019. "Differentiation of Bioengineered Skeletal Muscle Within a 3D Printed Perfusion Bioreactor Reduces Atrophic and Inflammatory Gene Expression". figshare.

https://hdl.handle.net/2134/9938102.v1. 
Differentiation of bioengineered skeletal muscle within a 3D printed perfusion bioreactor reduces atrophic and inflammatory gene expression

Rowan P. Rimington ${ }^{1}$, Andrew J. Capel ${ }^{1}$, Kerry F. Chaplin ${ }^{1}$, Jacob W. Fleming ${ }^{1}$, H.C. Hemaka Bandulasena ${ }^{4}$, Richard J. Bibb ${ }^{3}$, Steven D. R. Christie ${ }^{2}$, Mark P. Lewis ${ }^{1 *}$

${ }^{1}$ National Centre for Sport and Exercise Medicine, School of Sport, Exercise and Health Sciences, Loughborough University, Loughborough, Leicestershire, LE11 3TU, UK.

${ }^{2}$ School of Science, Loughborough University, Loughborough, Leicestershire, LE11 3TU, UK.

${ }^{3}$ Design School, Loughborough University, Leicestershire, Loughborough, LE11 3TU, UK.

${ }^{4}$ School of Aeronautical, Automotive, Chemical and Materials Engineering, Department of Chemical Engineering, Loughborough University, Leicestershire, Loughborough, LE11 3TU, UK.

Electronic supplementary information (ESI) available

\section{*Corresponding Author:}

Professor Mark Lewis

E: M.P.Lewis@,lboro.ac.uk 


\begin{abstract}
Bioengineered skeletal muscle tissues benefit from dynamic culture environments which facilitate the appropriate provision of nutrients and removal of cellular waste products. Biologically compatible perfusion systems hold the potential to enhance the physiological biomimicry of in vitro tissues via dynamic culture, in addition to providing technological advances in analytical testing and live cellular imaging for analysis of cellular development. To meet such diverse requirements, perfusion systems require the capacity and adaptability to incorporate multiple cell laden constructs of both monolayer and bioengineered tissues. This work reports perfusion systems produced using additive manufacturing (AM) technology for the in situ phenotypic development of myogenic precursor cells in monolayer and bioengineered tissue. Biocompatibility of systems 3D printed using stereolithography (SL), laser sintering (LS) and PolyJet outlined preferential morphological development within both SL and LS devices. When exposed to intermittent perfusion in monolayer, delayed yet physiologically representative cellular proliferation, MyoD and myogenin transcription of $\mathrm{C}_{2} \mathrm{C}_{12}$ cells was evident. Long-term ( 8 days) intermittent perfusion of monolayer cultures outlined viable morphological and genetic in situ differentiation for the live cellular imaging of myogenic development. Continuous perfusion cultures (13 days) of bioengineered skeletal muscle tissues outlined in situ myogenic differentiation, forming mature multinucleated myotubes. Here, reductions in IL-1 $\beta$ and TNF- $\alpha$ inflammatory cytokines, myostatin and MuRF-1 atrophic mRNA expression were observed. Comparable myosin heavy chain (MyHC) isoform transcription profiles were evident between conditions; however, total mRNA expression was reduced in perfusion conditions. Decreased transcription of MuRF1 and subsequent reduced ubiquitination of MyHC protein, alludes to a decreased requirement for transcription of MyHC isoform transcripts. Together, this data appears to indicate that 3D printed perfusion systems elicit enhanced stability of the culture environment, resulting in a reduced basal requirement for MyHC gene expression within bioengineered skeletal muscle tissue.
\end{abstract}

Key words: Perfusion, Skeletal Muscle, Tissue Engineering, 3D Printing, Additive Manufacturing. 


\section{Introduction}

Tissue engineered skeletal muscle models, focussed on the in vitro replication of the native in vivo niche have been utilised for the screening of nutrients, ${ }^{1}$ pharmacological agents, ${ }^{2,3}$ modelling of pathological conditions ${ }^{4-}$ ${ }^{8}$ and with a view to complementing host tissue regeneration following implantation. ${ }^{9}$ The progression of these models has been evidenced in the maturation of in vitro muscle produced in laboratory environments; ${ }^{3,5,9-17}$ however, further physiological and technological advancements are required for the utility of these models to be fully realised. Currently a focus toward creating peripheral interactions between surrounding in vivo cell types within three-dimensional (3D) matrices, predominates the literature. ${ }^{18}$ Although such developments have shown the capability to enhance skeletal muscle contractile functionality ${ }^{19}$ and vasculature nutrient delivery, ${ }^{9}$ little work has been undertaken with regard to replicating the perfused nature of the skeletal muscle cellular macroenvironment.

The concept of providing perfused medium to engineered tissue is essential when seeking to replicate the physiological in vivo niche. Continuous replenishment and removal of cellular medium facilitates the consistent delivery of nutrients and removal of cellular waste products, preventing fluctuations in molecules which have potential cell signalling roles. In addition, perfusion systems may also hold utility in the long-term generation of regenerative tissue constructs for implantation. Sealed systems ensure sterility and automated medium replenishment over extensive culture periods, which has resulted in enhanced structural maturation of engineered cardiac muscle tissue. ${ }^{20}$ Perfusion culture has previously been undertaken using miniaturised desktop cell culture incubators, ${ }^{21-26}$ incubated flow chambers ${ }^{27-29}$ and commercial systems,${ }^{30}$ with differing systems utilising a variety of mammalian cell types. Increases in uniform seeding of $\mathrm{C}_{2} \mathrm{C}_{12}$ murine skeletal myoblasts and neonatal rat cardiac myocytes has been reported via perfusion of porous polymer scaffolds. ${ }^{31}$ Commercial platforms which allow 3D muscle-like tissues to be cultured within a perfused environment have been demonstrated, however, such tissue lacks a physiological aligned structure in addition to low levels of myogenic differentiation. ${ }^{32}$ Bespoke devices have also been created for chip based cultivation of myoblast cells in monolayer; although culture periods were confined to $26 \mathrm{~h}^{33}$ The long term maintenance of tissue engineered skeletal muscle has been achieved for 30 days in a commercial bioreactor system; ${ }^{30,34}$ however, hydrogels reported are differentiated to form aligned myotubes within standard static culture environments for 
14 days prior to perfusion. Therefore, no current system exists which can support the generation of highly aligned, functional tissue engineered muscle throughout its development.

In addition to potential physiological benefits, perfusion systems also present significant potential in pharmaceutical drug discovery, toxicology and high-throughput screening processes via automated, controlled and accurate delivery of cellular reagents. Bioengineering of skeletal muscle has been adapted and scaled using automated technology, in order to provide biomimetic tissue for such pharmaceutical drug analysis. ${ }^{35,36}$ However, these models predominantly remain within static plate based assays. ${ }^{37}$ The emergence of microfluidics has resulted in a plethora of cellular devices aimed to facilitate the rapid screening of pharmacological stimulants. ${ }^{22,38,39}$ Recent work has demonstrated the development of static monolayer neuromuscular junctions ${ }^{40}$ and chip based tissue engineered skeletal muscle, ${ }^{2}$ as well as microfluidic perfused sarcomere dynamics. ${ }^{41}$ Although such devices hold utility in a multitude of settings, the time consuming and complex soft lithographic techniques required reduces the wide-ranging translation of these methods. To truly influence pharmaceutical drug screening, an automated perfusion system that is capable of both generating and analysing multiple arrays of engineered tissue is required.

Advancements in 3D printing also known as additive manufacture (AM) technology has markedly enhanced the efficiency of creating fluidic devices for chemical and biological applications, ${ }^{42-50}$ in part due to the development of inexpensive user-friendly desktop printers. As such, biocompatible polymers are now evident across a range of $\mathrm{AM}$ techniques. ${ }^{51} 3 \mathrm{D}$ printing technology provides a variety of advantages when producing functional systems, with designs also translatable to future mass production. Rapid iterations of designs allow for fluidity when developing technology, with future designs also holding the capacity for customisation toward experiment specific physiological models. 3D printed perfusion devices have been developed using PolyJet $^{52}$ and dual extrusion fused deposition modelling (FDM) technology, ${ }^{53}$ validated using monolayer primary rat hepatocyte and human osteoblast scaffold cultures respectively. Although viable populations are evident, the flexibility of designs for the integration of multiple tissue engineered constructs appears limited due to their bespoke nature. In order to fully exploit the vast benefits of perfusion-based cell culture, reproducible and accessible systems that are receptive to multiple cell laden constructs (monolayer and 3D tissues) that facilitate complete in situ phenotypic development are desirable. Designs for perfusion devices require both real-time and end point sacrificial analytical capability to allow accurate data to be collected. In 
addition, scalable systems that satisfy both the long-term growth of regenerative tissue for implantation, as well as multiple arrays of constructs at decreasing cell number for high-throughput rapid screening applications are essential design criteria.

This work demonstrates adaptable and scalable 3D printed biocompatible perfusion systems derived across multiple AM processes; stereolithography (SL), laser sintering (LS) and PolyJet. To aid the translation of this work, all designs reported are freely available to download, print, and use from the following URL: https://figshare.com/projects/3D_Printed_Bioreactors/36446. These designs will allow researchers who do not have access to commercially available bioreactor technologies to undertake and develop fundamental research into musculoskeletal physiology, utilising an established tissue engineered musculoskeletal model, within a perfused environment that more accurately recapitulates the physiological in vivo niche. Biocompatibility and feasibility of each device are evaluated, prior to optimisation of cellular proliferation in response to perfusion environments. Viable long-term perfusion cultures of monolayer (8 days); for optical real-time visualisation, and bioengineered 3D murine skeletal muscle tissue (13 days) that undergo myogenic differentiation in situ to form multinucleated myotubes are then presented. To the authors knowledge, this is the first example of highly aligned, mature and functional engineered skeletal muscle being cultured within a dynamic environment throughout both the growth and differentiation phase. This significantly will allow investigation into the tissue response to external stimuli across the entire tissue developmental timeline. Here the murine myoblast $\mathrm{C}_{2} \mathrm{C}_{12}$ cell line has been utilised due to its capacity to afford a physiologically relevant model of skeletal muscle, however primary human tissue has also been previously demonstrated within this engineered mould, ${ }^{36}$ allowing simple translation for researchers wishing to undertake research investigating human musculoskeletal physiology.

\section{Materials and methods}

\subsection{D printing}

3D printing was undertaken utilising the following processes and parameters: FormLabs Form $2^{\mathrm{TM}}$ machine using the clear resin FLGPCL02 set at 0.1 mm layer thickness. Ultimaker $2+$ at previously published settings. ${ }^{51}$ Stratasys Objet Connex 500 ${ }^{\mathrm{TM}}$ using the VeroClear-RGD810 material (with SUP705 support material) set at $0.33 \mathrm{~mm}$ layer thickness and default speed/quality settings. EOS Formiga P100TM using EOS PA2200 powder (PA-12) at $0.1 \mathrm{~mm}$ layer thickness. 3D computer aided design (CAD) modelling was performed using Siemens 
NX software (v8.5, Siemens) with completed .stl files verified using Materialise MiniMagics (Materialise NV). Completed .stl files were processed using manufacturer recommended software for each process. Clear FLGPCL02 (Clear-FL) samples were removed from the build plate and cleaned in isopropanol to remove uncured resin, prior to being submersed and agitated in $70 \%$ industrial methylated spirit (IMS) for $\leq 30$ mins. VeroClear-RGD810 (VeroClear) and PA-12 samples were removed from build plates and cleaned using a soft abrasive brush to remove supports and un-sintered powder respectively.

\subsection{Perfusion system design}

Within modular designs, optically transparent coverslips (Top and bottom, Fig. 1b2) or tissue engineered constructs (Bottom only, Fig. 5c, d) are placed onto PDMS O-rings (Fig. 1b3); cast from polylactic acid (PLA) moulds 3D printed using FDM, and inserted into devices (Fig. 1b5) prior to being sealed using a PLA 3D printed thread (FDM, Fig. 1b1 and b4). Designs that incorporate tissue engineered moulds (modular or integrated) require sealing with optical coverslips on the top of the device. Once sealed, medium entry is achieved using an automated Aladdin AL-1000 syringe pump. Polypropylene female luer hose barb adapters (Cole-Palmer) are used to connect syringes (BD Plastipak; 20 or $50 \mathrm{~mL}$ ) to $1.6 \mathrm{~mm}$ internal diameter (ID) $\varnothing$ silicone tubing (Cole-Palmer) which are coupled to 3D printed inlet (Fig. 1b7a) and outlets (Fig. 1b7b) via hose barb ports.

\subsection{Cell culture}

$\mathrm{C}_{2} \mathrm{C}_{12}$ murine skeletal myoblasts, all below passage 10 (ECACC, Sigma, UK), were cultured in T80 flasks (Nunc $^{\mathrm{TM}}$, Fisher Scientific, UK) and incubated at $5 \% \mathrm{CO}_{2}$ atmosphere and $37^{\circ} \mathrm{C}$ (HERA cell 240i, Thermo Fisher, UK) in growth medium (GM); composed of $79 \%$ DMEM (Sigma), $20 \%$ FBS (Pan Biotech) \& $1 \%$ penicillin-streptomycin (Fisher) until $80 \%$ confluence was obtained. Each experimental/technical repeat was conducted at a standardised biological passage for both the control and experimental conditions. All monolayer cell cultures were seeded at a density of $1 \times 10^{4}$ cells per $\mathrm{cm}^{2}$. Incubated cells GM was changed every $24 \mathrm{~h}$ until confluence was attained, prior to transfer into differentiation medium (DM); $97 \%$ DMEM, $2 \%$ horse serum (Sigma) \& $1 \%$ penicillin-streptomycin, with monolayer cell cultures DM changed once after $72 \mathrm{~h}$, prior to remaining in culture for a further $48 \mathrm{~h}$ unless specifically detailed. All cell cultures within $3 \mathrm{D}$ printed devices incubated at $5 \% \mathrm{CO}_{2}$ were covered using sterile permeable membrane Aeraseal ${ }^{\mathrm{TM}}$ film (Sigma) to facilitate gaseous exchange. All experiments conducted were derived from $n=3$ experimental repeats per condition. 


\subsection{D Skeletal muscle tissue engineering}

Collagen/Matrigel ${ }^{\circledR}$ hydrogels were formed by the addition of $65 \% \mathrm{v} / \mathrm{v}$ type I rat tail collagen; dissolved in $0.1 \mathrm{M}$ acetic acid, protein at $2.035 \mathrm{mg}$ per $\mathrm{mL}$ ), with $20 \%$ Corning Matrigel ${ }^{\circledR}$ matrix and $10 \% \mathrm{v} / \mathrm{v}$ of $10 \mathrm{X}$ MEM. ${ }^{36}$ This solution was neutralised by the dropwise addition of $5 \mathrm{M}$ and $1 \mathrm{M}$ sodium hydroxide $(\mathrm{NaOH})$, until a colour change to cirrus pink was observed. Cells were added at a seeding density of $4 \times 10^{6}$ cells per $\mathrm{mL}$ in a $5 \% \mathrm{v} / \mathrm{v}$ GM solution to pre-sterilised control or flow system mould and incubated for 10-15 minutes $\left(37^{\circ} \mathrm{C}, 5 \% \mathrm{CO}_{2}\right)$. Once set, skeletal muscle hydrogels were immersed in $2 \mathrm{~mL}$ GM. All tissue engineered constructs were cultured for 14 days (4 days GM, 10 days DM). Measuring the reducing width of constructs provides an indication of cell attachment and matrix remodelling, previously reported by our group. ${ }^{12}$ To do so, macroscopic images were taken of hydrogels at 2 and 14 days in culture. The amount of construct deformation was determined by subtracting the area of the hydrogel from the original mould area in which the construct was set and expressed as percentage reduction.

\subsection{Immunocytochemistry, fluorescence staining and morphological analysis}

Immunofluorescence of monolayer cell cultures at experimental termination were washed twice in $2 \mathrm{~mL}$ phosphate buffered saline (PBS) per well, fixed (3.7\% paraformaldehyde), permeabilised $(0.2 \%$ Triton X100, Fisher) and stained using F-actin molecular probe rhodamine phalloidin (1:200; Life Technologies, Molecular Probes). DAPI nuclear stain (1:2000; Life Technologies, Molecular Probes) was used to stain nuclei. Live staining of $\mathrm{C}_{2} \mathrm{C}_{12}$ was undertaken via addition of mitochondrial live stain Mitotracker ${ }^{\mathrm{TM}}$ Red CMXRos (1 nM, Thermo Fisher) and bisBenzimide Hoescht 33342 trihydrochloride (20 $\mu \mathrm{M}$, Sigma) nuclear stain to serumfree medium (99\% DMEM, $1 \%$ penicillin-streptomycin). Cells were washed twice in $2 \mathrm{~mL}$ PBS per well prior to $\geq 1 \mathrm{~h}$ incubation at $37^{\circ} \mathrm{C}, 5 \% \mathrm{CO}_{2}$ atmosphere. Rhodamine phalloidin and Mitotracker ${ }^{\mathrm{TM}}$ were excited at $540 \mathrm{~nm}$ and $579 \mathrm{~nm}$, and emitted at $565 \mathrm{~nm} 599 \mathrm{~nm}$ respectively and appear red in fluorescence images. DAPI and Hoescht 333432 were excited at $358 \mathrm{~nm}$ and $346 \mathrm{~nm}$ and emitted at $461 \mathrm{~nm}$ and $460 \mathrm{~nm}$ respectively and appear blue. Tissue engineered constructs were fixed using 50/50 methanol acetone solution. To undertake ICC, hydrogels were permeabilised for 30 minutes and blocked $5 \%$ goat serum for 30 minutes, prior to being incubated overnight $(\geq 12 \mathrm{~h}$ ) with monoclonal mouse $\alpha$-actinin mouse IgG1 A7811 (1:200). Primary antibodies were co-incubated with additional $5 \%$ goat serum. $\mathrm{C}_{2} \mathrm{C}_{12}$ skeletal muscle hydrogels labelled with monoclonal $\alpha$-actinin were counterstained simultaneously with AlexaFluor ${ }^{\circledR} 488$-conjugated goat anti mouse $\operatorname{IgG}(1: 200)$ 
secondary fluorochrome and F-actin molecular probe rhodamine phalloidin ( $\geq 2 \mathrm{~h}$ ). Cells were washed three times $(1 \mathrm{x}$ TBS) before permeabilisation and after both primary and secondary antibody incubations. AlexaFluor $\AA 488$ appears green and is indicative of $\alpha$-actinin at standardised exposures.

Fluorescence images were visualised using a Leica DM2500 fluorescence microscope (10 and 20x) with manufacturer's software (Leica Application Suite X). Confocal imaging was undertaken on a Zeiss LSM 880, using 40x oil objective. Images captured via confocal tile scan are stitched together enabling visualisation of the whole construct. One scan equates to a $3 \times 7$ image tiles, eliciting 21 images taken as a single $z$-slice from the centre of the construct. Images were analysed using IMAGE J 1.50a/Fiji (Java 1.6.0_24) software (National institute of Health, Bethesda, MD, USA) ${ }^{54}$ Monolayer image inclusion criteria $(n=1)$ were set at $\geq 5$ images taken at random locations per well. Myotube inclusion criteria were defined as containing $\geq 3$ nuclei per myotube. Cumulative frequencies were calculated to determine the number of myotubes necessitated per image for each analysis. Fusion index analysis was determined as the number of fused nuclei; nuclei residing within myotubes, divided by total nuclei per image frame and expressed as a percentage. Myotube density is undertaken by drawing a line across the width of skeletal muscle hydrogels and measuring the number of myotubes that transect this line. This is performed at three regions (upper, middle and lower) of the construct. The width of each construct is divided by 100, with the mean number of transecting myotubes from the three regions being divided by this value; resulting in a density value expressed as myotubes per $100 \mu \mathrm{m}$. This value is then multiplied by myotube width to yield the percentage of the hydrogel that is covered by myotubes. Analysis of nuclei number was performed using an in-house macroinstruction designed for Fiji (Java 1.6.0_24) image analysis software (Image J 1.50a).

\subsection{RNA extraction and quantitative RT-PCR}

Prior to extraction, tissue engineered constructs were thawed and suspended in $500 \mu 1$ TRIzol before being homogenised using TissueLyserII (Qiagen) set at a frequency of 20 for $\geq 2$ minutes until tissue degradation was apparent. RNA was extracted using the TRIzol method, according to manufacturer's instructions (Sigma). RNA concentration and purity were obtained by UV spectroscopy at optical density (ODs) of 260 and $280 \mathrm{~nm}$ using a Nanodrop 2000 (Fisher, Rosklide, Denmark). All RNA samples were analysed in duplicate. Five nanograms of RNA were used per RT-PCR reaction for RPII- $\beta$, MyoD, myogenin (myog), mki-67, myostatin (MSTN), IL-1 $\beta$, IL-6, TNF- $\alpha$, MuRF-1, MaFbx (Fbxo32), MYH3, MYH8, MYH7, MYH2 and MYH1 (Table 
S1). RT-PCR amplifications were carried out using Power SYBR Green RNA-to-CT 1 step kit (Qiagen) on a ViiATM Real-Time PCR System (Applied bio-systems, Life Technologies), analysed using ViiATM 7RUO Software. RT-PCR procedure was as follows: $50^{\circ} \mathrm{C}, 10 \mathrm{~min}$ (for cDNA synthesis), $95^{\circ} \mathrm{C}, 5 \mathrm{~min}$ (transcriptase inactivation), followed by $95{ }^{\circ} \mathrm{C}, 10 \mathrm{sec}$ (denaturation), $60{ }^{\circ} \mathrm{C}, 30 \mathrm{sec}$ (annealing/extension) for 40 cycles. Relative gene expression was calculated using the comparative $\mathrm{C}_{\mathrm{T}}\left(\Delta \Delta \mathrm{C}_{\mathrm{T}}\right)$ equation for normalised expression ratios; relative expression calculated as $2-\Delta \Delta C_{T}$, where $C_{T}$ is representative of the threshold cycle. ${ }^{55}$ RPII- $\beta$ was used as the housekeeping gene in all RT-PCR assays. To compare conditions, one control sample from each experimental repeat ( $\mathrm{n}=3$ ) was used as the calibrator condition in the $\mathrm{C}_{T}\left(\Delta \Delta \mathrm{C}_{T}\right)$ equation. RT-PCR data is presented as relative gene expression level, determined by the $\Delta \Delta \mathrm{C}_{\mathrm{T}}$ equation.

\subsection{Numerical simulations}

Numerical simulations were performed for both the monolayer and the tissue engineered perfusion systems to study flow patterns within the device and to calculate the shear stresses on the monolayer and gel surfaces. Streamlines generated from these computations are useful in identifying stagnation zones within the device that would limit convective mass transfer. Shear stresses on the monolayer and the gel surface due to the fluid flow is an important factor in ensuring suitable environment for cell growth and survival. Full 3D geometries of the devices were used as the computational domain for the numerical simulations. The Reynolds number at the inlet of the bioreactor was estimated to be $<<1$ for all operating conditions, therefore fluid inertia was neglected. The governing equations for the fluid flow problem are continuity and incompressible NavierStokes equation for laminar flow (creeping flow as inertia is neglected):

$$
\begin{aligned}
& \nabla \cdot \boldsymbol{u}=0 \\
& 0=\nabla \cdot\left[-p I+\eta\left(\nabla \boldsymbol{u}+\nabla \boldsymbol{u}^{T}\right)\right]
\end{aligned}
$$

where $u, p, I, \rho$ and $\eta$ denotes the velocity field, pressure, identity matrix, density and dynamic viscosity respectively.

The inlet boundary condition was set according to the liquid flow rate supplied to the device while the outlet boundary condition was set to zero pressure. All the other boundaries (perfusion system solid walls and gel surfaces) were set as no-slip conditions. The fluid was modelled as DMEM with fluid properties evaluated at $37^{\circ} \mathrm{C}$ : viscosity $=8.4 \times 10-4 \mathrm{~kg} \mathrm{~m}{ }^{-3}$ and fluid density $=1009 \mathrm{~kg} \mathrm{~m}-3 .{ }^{56}$ Mesh independent solutions were 
obtained by discretising the computational geometry using 1434640 tetrahedral mesh elements. The problem was solved in dimensional form at steady state using Galerkin finite element method (FEM) with Comsol Multiphysics V5.3a. Computations were performed on an Intel Core i5 $64 \mathrm{bit} 2.7 \mathrm{GHz}$ processor and the computation time was approximately $2 \mathrm{~h}$ for each case. A liquid flow rates of $1 \mathrm{~mL}$ per min was used for the monolayer while a range of flow rates from $250 \mu \mathrm{L}$ per h to $2 \mathrm{~mL}$ per $\mathrm{h}$ were tested for the tissue engineered perfusion system.

\subsection{Biological compatibility of 3D printed perfusion system microenvironment}

Preceding each experiment, perfusion systems fabricated from Clear-FL and VeroClear resins were prepared as previously described.$^{57}$ All flow devices were then immersed and agitated in $70 \%$ IMS for $\leq 30$ mins before being sterilised via ultraviolet (UV) light for $\geq 1 \mathrm{~h}$. Once prepared, $\mathrm{C}_{2} \mathrm{C}_{12}$ cells were seeded onto $2 \times 20 \mathrm{~mm} \varnothing$ optical glass coverslips coated with $1 \mathrm{~mL} 0.2 \%$ gelatin solution (Sigma) within either Clear-FL, VeroClear, or PA-12 perfusion system environments, or tissue culture plate positive control (PC). Cells were then fixed for fluorescence imaging at DM120 h time-points to determine morphological cellular phenotype. Initial prior observations outlined that cells cultured within Clear-FL (SL) perfusion systems displayed a continual degradative phenotype across experimental repeats $(n=3)$, however this was recovered when devices were exposed to further leachate periods between $n=3$ and $n=4$ (Fig. S4), outlining the requirement for interrepeat treatment of flow cells manufactured using this process. Inter-repeat and post printing leachate time was subsequently optimised to a threshold of $\geq 3 \mathrm{~h} \mathrm{UV} \mathrm{O-ZONE} \mathrm{treatment,} 24 \mathrm{~h} 70 \% \mathrm{IMS}$, and 2 days aqueous post printing leachate, and $24 \mathrm{~h} \mathrm{70 \%} \mathrm{IMS} \mathrm{plus} 24 \mathrm{~h}$ aqueous leachate inter-repeat (Fig. S5, S6 and S7). This protocol was then implemented for all Clear-FL devices. Due to the bio-inert properties of PA-12 such devices required no prior leachate time. Leachate required for VeroClear flow devices post printing was not optimised due to initial observations of reduced biological compatibility within this device at established maximal durations (11 days).

\subsection{Proliferation rates of $C_{2} C_{12}$ in $3 D$ printed systemic perfusion environment}

To analyse rates of proliferation within Clear-FL perfusion systems, $\mathrm{C}_{2} \mathrm{C}_{12}$ cells were seeded within either tissue culture plate positive control, static Clear-FL controls; incubated within standard cell culture $\left(37^{\circ} \mathrm{C} 5\right.$ $\% \mathrm{CO}_{2}$; Static Control) or microscope incubators $\left(37^{\circ} \mathrm{C}\right.$; Atmospheric Control). Clear-FL perfusion conditions were also maintained at $37^{\circ} \mathrm{C}$ within the microscope incubator (Solent Scientific), with $25 \mathrm{mM}$ concentration 
4-(2-Hydroxyethyl) piperazine-1-ethanesulfonic acid (HEPES) added to sterile filtered GM and DM of all conditions in order to buffer the medium $\mathrm{pH}$ in absence of $5 \% \mathrm{CO}_{2}$ in perfusion and atmospheric control conditions. Cells were then left for $24 \mathrm{~h}$ to adhere, prior to being cultured until confluence was achieved. Perfusion conditions medium was changed via Aladdin AL-1000 syringe pump (World Precision Instruments) at a rate of $1 \mathrm{~mL}$ per min for 4 mins duration at $24 \mathrm{~h}$ intervals. This rate and duration resulted in four complete replenishments of the perfusion environment to ensure total replacement of the medium. To ascertain the timepoint at which cellular confluence was achieved, all conditions were incubated in serum free medium containing $20 \mu \mathrm{M}$ Hoescht and $1 \mathrm{nM}$ Mitotracker ${ }^{\mathrm{TM}}$ to undertake live fluorescence microscopy at 24, 72 and $96 \mathrm{~h}$ in culture. Once morphological proliferation analysis had been conducted, cells either continued in culture (24 h) or were then washed twice with $2 \mathrm{~mL}$ PBS, prior to RNA isolation with cells being immersed and homogenised in $0.5 \mathrm{~mL}$ TRIzol per well (GM72 and $96 \mathrm{~h}$ only).

\subsection{Long term myogenic perfusion cultures of monolayer $\mathrm{C}_{2} \mathrm{C}_{12}$ skeletal muscle cells}

Cells were seeded within positive control, PA-12 static control and perfusion devices at previously described densities. Cells were left to adhere to $20 \mathrm{~mm} \varnothing$ glass coverslips for $24 \mathrm{~h}$ before being transferred to microscope incubator (perfusion) or retained within standard culture incubator environments (PC, static control). As previously optimised, cells were then exposed to perfusion environments for a further $72 \mathrm{~h}$, being intermittently perfused at $1 \mathrm{~mL}$ per min flow rate for 4 mins at $24 \mathrm{~h}$ intervals until confluence was attained. At the point of confluence, the syringe was replaced to include DM + $25 \mathrm{mM}$ HEPES, with cells being perfused for a further $120 \mathrm{~h}$; totalling 8 days in perfusion culture until multinucleated myotubes were obtained. Cells were then incubated in serum free medium containing $20 \mu \mathrm{M}$ Hoescht and $1 \mathrm{nM}$ Mitotracker $^{\mathrm{TM}}$ for fluorescence imaging, prior to autologous RNA isolation yielding two analyses per flow chamber within optical perfusion cultures.

\subsection{In situ phenotypic development of murine tissue engineered skeletal muscle within 3D printed perfusion system}

$\mathrm{C}_{2} \mathrm{C}_{12}$ murine skeletal myoblasts were seeded within collagen/Matrigel ${ }^{\circledR}$ hydrogels as previously described in either 3D printed LS PA-12 perfusion systems (50 $\mu$ L construct volumes at a density of $4 \times 10^{6}$ per $\mathrm{mL}$ ) or PA-12 3D printed mould in a culture well plate (Control). Cells were then incubated in $2 \mathrm{~mL}$ GM and left for $24 \mathrm{~h}$ for initial attachment and matrix remodelling. After $24 \mathrm{~h}$ in culture, control skeletal muscle hydrogels were changed to GM containing $25 \mathrm{mM}$ HEPES for $72 \mathrm{~h}$, prior to inducing differentiation (DM $+25 \mathrm{mM}$ 
HEPES) for 10 days. Perfusion systems containing hydrogels were sealed using PDMS O-rings and $20 \mathrm{~mm} \varnothing$ optical glass coverslips to ensure sample macroscopic visualisation. Silicone tubing was then added to hose barb connectors as previously described, prior to being continuously perfused with 25mM HEPES GM for 72 h. Perfusion system syringes were then changed to contain 25mM HEPES DM for 10 days, totalling 13 days of continuous perfusion culture at a rate of $250 \mu \mathrm{L}$ per h. Due to the non-optical nature of tissue engineered perfusion systems, both control and perfusion culture were undertaken within standard cell culture incubators $\left(37^{\circ} \mathrm{C}, 5 \% \mathrm{CO}_{2}\right)$. The silicone tubing utilised is permeable to gaseous diffusion, as such appropriate buffering and oxygenation of the medium would be achieved prior to entering the sealed device. Perfusion and representative control moulds were designed for multiple analyses with two hydrogels in each well per perfusion device. At this point one hydrogel was isolated for mRNA analyses, with remaining constructs being fixed for immunocytochemistry; yielding two analyses per perfusion system from a singular environment.

\subsection{Statistical analysis}

Where parametric assumptions were met, a 3 x 4 ANOVA was used for nuclear number proliferation analyses, $2 \times 4$ for proliferation gene expression and $2 \times 2$ for construct deformation analyses. $1 \times 5$ ANOVA was undertaken to ascertain differences in the ratio of myosin heavy chain expression within conditions (control and perfusion), prior to 2 x 5 ANOVA to analyse differences between conditions. One-way ANOVA was used to analyse single gene mRNA expression and morphological data concerned with experimental termination time-points. Where significant interactions were observed, Bonferroni post-hoc analyses were used to analyse differences between conditions at specific time-points. Non-parametric Kruskal-Wallis $(H)$ analysis was undertaken where data violated parametric assumptions. Mann-Whitney $(U)$ tests were then utilised to determine significance between conditions, in accordance with Bonferroni correction to account for incremental type-1 error. All data is reported as mean \pm standard deviation (SD). Significance was assumed at $\mathrm{P} \leq 0.05$. 


\section{Results}

\subsection{Numerical simulations and biological compatibility of 3D printed perfusion systems}

Results from the numerical simulations for the monolayer perfusion system are shown in Fig. 1c. As the fluid enters the bioreactor, a recirculation zone is developed at the entrance towards the top half of the bioreactor. However, streamlines for the bottom half of the reactor are parallel to the monolayer and demonstrates transport of fresh feed to the cells on a regular basis. The computed shear stress on the bottom surface of the reactor is limited to $\sim 8.24 \mathrm{~Pa}$ indicating a low shear environment near the monolayer. This is an important factor in designing cellular perfusion bioreactors as potential cell damage due to stresses arising from fluid flow should be minimized. Shear rates within the computational domain is also presented to demonstrate the low shear environment prevalent within the system. A maximum shear rate of $\sim 2 \mathrm{~s}^{-1}$ is observed at the inlet and outlet while a negligible shear rate is observed throughout larger proportion of the domain. Overall, numerical simulations ascertain that the design is suitable for the intended purpose as far as the transport phenomena are concerned.

Perfusion systems manufactured using SL, LS and PolyJet AM techniques were achieved via a single manufacturing step. All flow chambers comprised comparable internal design features independent of manufacture technique (Fig. 1a). Internal geometries of 3D printed perfusion systems were designed to mimic standard culture well-plate environments; cylindrical wells comprising incubated medium that covers a cellular population located beneath a gaseous zone. When cultured statically for 8 days within Clear-FL (SL) and PA12 (LS) perfusion microenvironments (Fig. 2a), $\mathrm{C}_{2} \mathrm{C}_{12}$ cells remained viable as measured by morphological phenotypes (Fig. 2b); myotube width (Fig. 2c), number (Fig. 2d), length (Fig. 2f), and nuclear fusion indexes (Fig. 2e) when compared to positive tissue culture plate controls. In VeroClear systems myotube widths were comparable, however reductions in myotube number $(\mathrm{P}=0.018)$, length $(\mathrm{P}=0.007)$ and nuclear fusion $(\mathrm{P} \leq$ 0.0005) were evident, suggesting inhibition of myogenic differentiation in response to VeroClear perfusion system microenvironments. The favourable biocompatibility and capacity to fabricate highly complex and intricate design features in PA-12 and Clear-FL devices, outlines LS and SL as the AM processes of choice for the creation of perfusion bioreactors. As such, within this work, Clear-FL designs are utilised for systems in which cells are cultured on glass coverslips, due to the commercial availability of SL printers. Designs printed via LS are used where cells are required to interact directly with the 3D printed mould due to the 
previously reported biocompatibility of this polymer for such applications. ${ }^{57}$
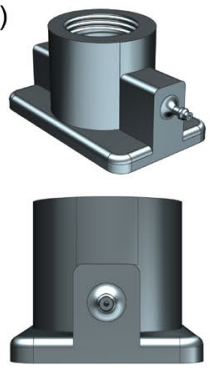
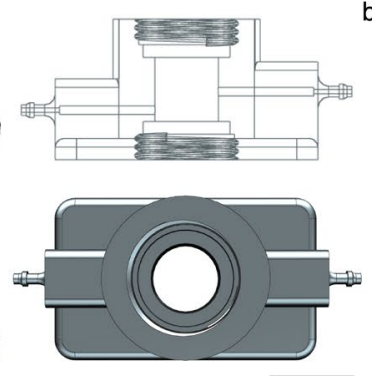
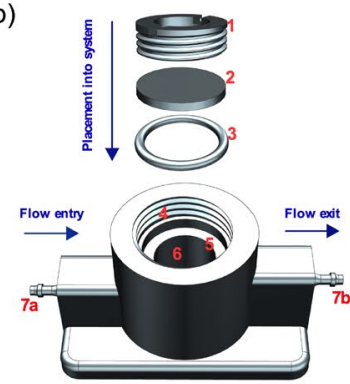

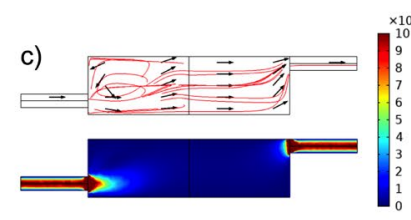

d)

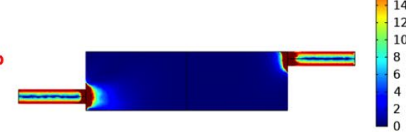

e)

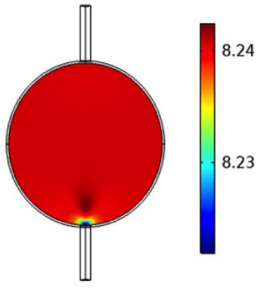

Fig.1. Computer aided design (CAD) models of perfusion systems. (a) detailing top, angled, side and detailed drawing views. (b) Schematic of perfusion system integration and flow directionality: ${ }^{1}$ Polylactic acid (PLA) 3D printed threaded insert via fused deposition modelling (FDM), ${ }^{2}$ Optical glass $(20 \mathrm{~mm} \varnothing)$ coverslip, ${ }^{3}$ poly-(dimethylsiloxane) (PDMS) O-ring cast from FDM PLA mould, ${ }^{4}$ Integrated thread, ${ }^{5}$ Ledge for O-ring/coverslip insertion, ${ }^{6}$ Internal culture well, ${ }^{7 a}$ Flow inlet and ${ }^{7 b}$ outlet hose barb connections. (c) Velocity magnitude $(\mathrm{m} / \mathrm{s})$, streamlines and velocity vectors from the numerical simulations for the cross-sectional plane across $\mathrm{X}=0$.

(d) Shear rate computed from the flow field $\left(\mathrm{s}^{-1}\right)$ for the cross-sectional plane across $\mathrm{Z}=0$. (e) Shear stresses on the bottom surface of the bioreactor $(\mathrm{Pa})$, where monolayer is present. bottom: Scale bars $=20 \mathrm{~mm}$. 
a)
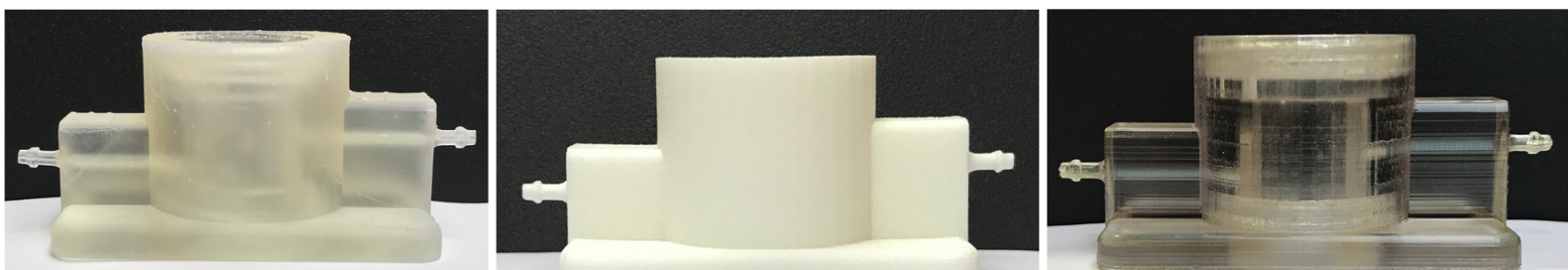

Clear-FL (SL)

\section{PA-12(LS)}

VeroClear (PolyJet)

b) $P$
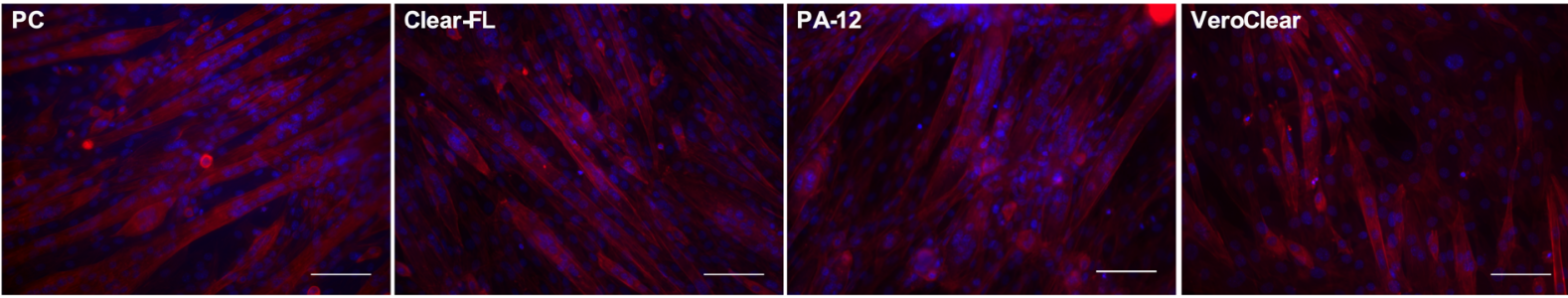

c)

d)

e)
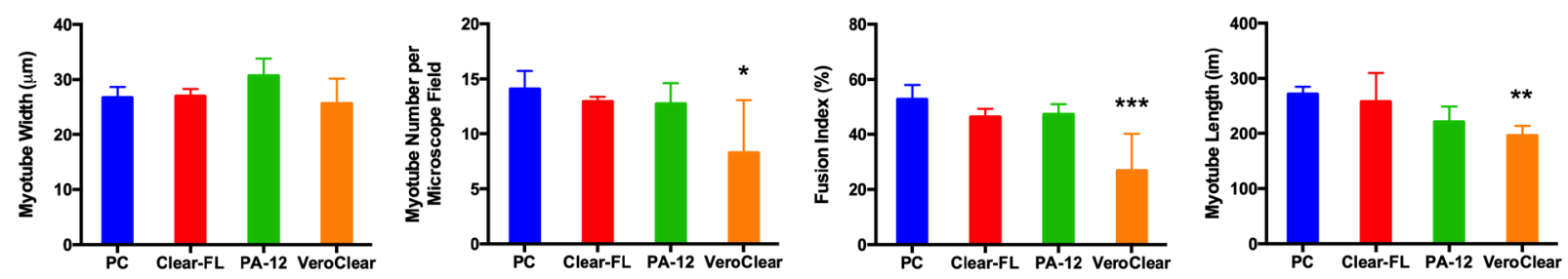

Fig.2. Biological compatibility of 3D printed perfusion system microenvironments. (a) Clear-FLGPCL02 (Clear-FL), PA-12 and VeroClear-RGD810 (VeroClear) perfusion systems. (b) Morphological staining of the actin cytoskeleton (red) and nucleic DNA (blue) of $\mathrm{C}_{2} \mathrm{C}_{12}$ cultured within 3D-printed perfusion system microenvironments and positive control (PC) at DM120 h time-points. (c) Myotube width (d) Myotube number (e) Fusion Index and (f) Myotube length of $\mathrm{C}_{2} \mathrm{C}_{12}$ after DM120 h culture. Significantly different from control; * $\mathrm{P} \leq 0.05, * * \mathrm{P} \leq 0.01, * * * \mathrm{P} \leq 0.0005$. Data are derived from $\mathrm{n}=3$ experimental repeats and presented \pm standard deviation (SD). Microscopy images 20x objective. Perfusion system scale bars $=20 \mathrm{~mm}$. Fluorescence scale bars $=100 \mu \mathrm{m}$. 


\subsection{Proliferation rates of $C_{2} C_{12}$ cells in response to perfusion culture}

The determine the effects of perfusion on cellular proliferation, the morphological and transcriptional activity of $\mathrm{C}_{2} \mathrm{C}_{12}$ cells were examined at flow rate regimes of $1 \mathrm{~mL}$ per minute for 4 minutes at $24 \mathrm{~h}$ intervals. Proliferation (Fig. 3a) rates of $\mathrm{C}_{2} \mathrm{C}_{12}$ were significantly decreased compared to positive control $(\mathrm{P} \leq 0.0005)$, once exposed to $48 \mathrm{~h}$ perfusion and atmospheric control conditions (GM72 h). Such reductions in cell number were recovered after $72 \mathrm{~h}$ perfusion (GM96 h) comparable to that of positive control (GM72 h). However, atmospheric control nuclei number remained significantly reduced $(\mathrm{P}=0.001)$ demonstrating beneficial characteristics of perfusion culture in 4-(2-Hydroxyethyl) piperazine-1-ethanesulfonic acid (HEPES) buffered atmospheric $\mathrm{CO}_{2}$ environments (Fig. 3b).

Myogenic transcriptional progression of $\mathrm{C}_{2} \mathrm{C}_{12}$ cells displayed comparable trends to morphological observations (Fig. 3c), with reduced MyoD expression at GM72 h in atmospheric control $(\mathrm{P}=0.003)$ and perfusion $(\mathrm{P}=0.027)$ Clear-FL devices. However, transcription of this gene recovered after GM96 $\mathrm{h}$ in both conditions. Similar trends were evident in the more advanced myogenic marker of myogenin after GM72 $\mathrm{h}$ in all Clear-FL device conditions; static control $(\mathrm{P}=0.05)$, atmospheric control $(\mathrm{P} \leq 0.0005)$ and perfusion $(\mathrm{P}=$ 0.001). Although expression of this gene increased at GM96 h, transcriptional levels remained significantly reduced in atmospheric control $(\mathrm{P} \leq 0.0005)$ and perfusion $(\mathrm{P}=0.006)$ conditions, outlining delayed yet physiologically representative myogenic development. Cell proliferation marker mki-67 displayed no significant differences between conditions; however non-significant increases in transcription of this gene appeared evident in perfusion conditions at both GM72 \& $96 \mathrm{~h}$, supporting the aforementioned assertion of delayed early myoblast differentiation (Fig. 3c). 


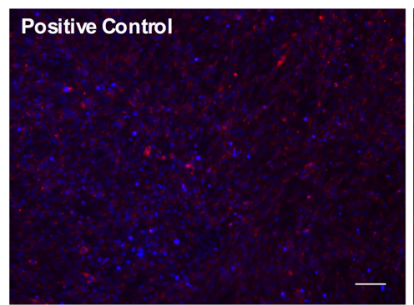

b)

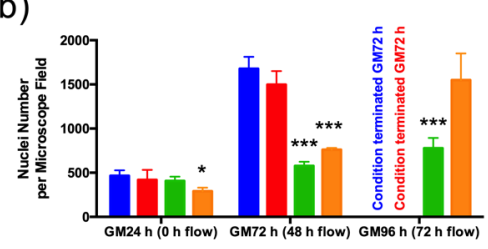

Positive Control

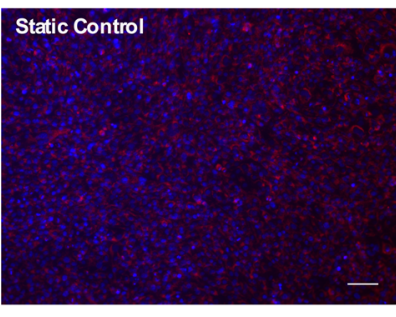

c)

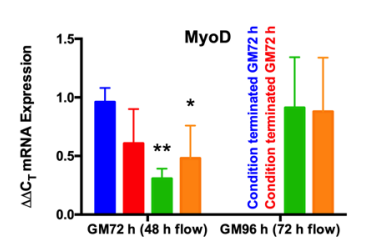

Static Control

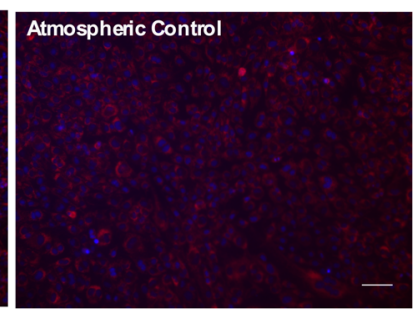

Perfusion
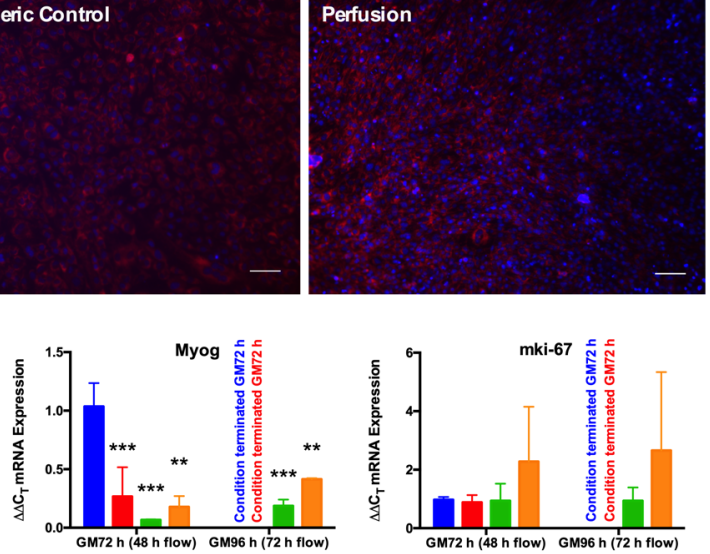

Atmospheric Control

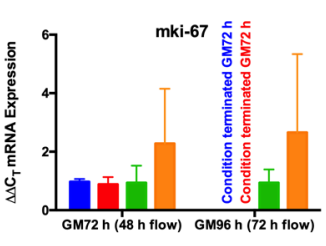

Perfusion

Fig. 3. Proliferation rates of $\mathrm{C}_{2} \mathrm{C}_{12}$ cells in response to perfusion culture. (a) Live morphological staining of mitochondria (red) and nucleic DNA (blue) of $\mathrm{C}_{2} \mathrm{C}_{12}$ cultured within Clear-FLGPCL02 (Clear-FL) 3D-printed perfusion system at GM72 and GM96 h time-points. (b) Nuclei number (c) MyoD, Myogenin (Myog) and mki-67 gene expression at GM72 and GM96 h time-points. No data generated for Positive or Static Controls at GM96 $h$ as cultures were terminated at the point of cellular confluence (GM72 h). Significantly different from control; * $\mathrm{P} \leq 0.05, * * \mathrm{P} \leq 0.01, * * * \mathrm{P} \leq 0.0005$. Data are derived from $\mathrm{n}=3$ experimental repeats and presented \pm standard deviation (SD). Microscopy images 10x objective. Scale bars $=100 \mu \mathrm{m}$. 


\subsection{Long term myogenic perfusion cultures of monolayer $\mathrm{C}_{2} \mathrm{C}_{12}$ skeletal muscle cells}

Physiologically representative morphological phenotypes (Fig. 4a) were observed in positive and static control conditions, with homogenous nuclei and myotube number, fusion index and myotube widths observed (Fig. $4 \mathrm{a}, \mathrm{c}, \mathrm{d}$ and $\mathrm{e}, \mathrm{P} \geq 0.05)$. Atmospheric control conditions, which had previously been demonstrated to not reach confluence after GM96 h (Fig. 3), were removed from the experimental setup. Although consistent nuclei number and myotube widths were evident in perfusion conditions $(P \geq 0.05)$, significant increases in the number of myotubes were apparent after 8 days perfusion culture $(1 \mathrm{~mL}$ per minute for 4 minutes at $24 \mathrm{~h}$ intervals, Fig. 4b). Such increases, when considered in context of comparable fusion index (Fig. 4e) outline morphological phenotypes of increased number at the expense of non-significant decreases in myotube length, observed (Fig. 4f, $P \geq 0.05$ ). No difference in myogenin mRNA expression was observed indicating terminally differentiated cultures in all conditions; however significant decreases were evident in MYH3 expression in perfusion conditions (Fig. 4g). 


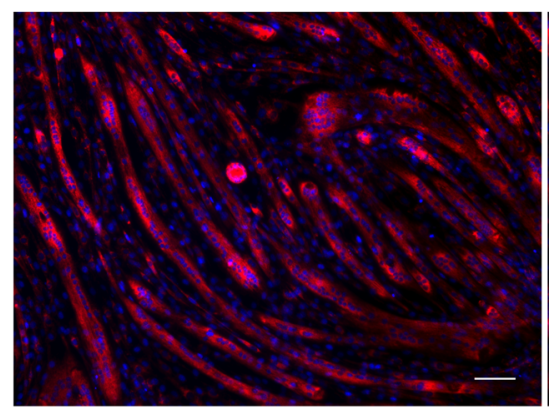

b)

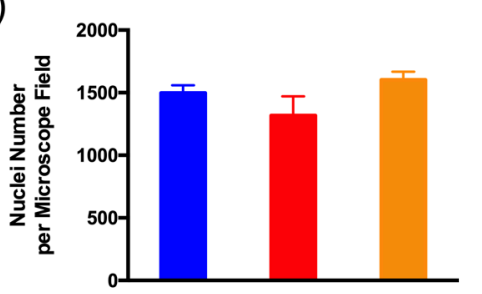

e)

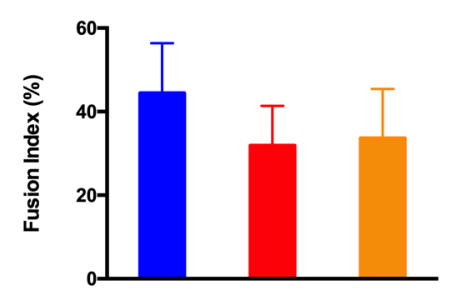

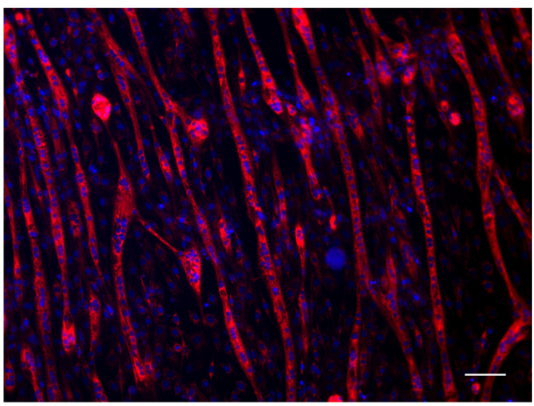

c)

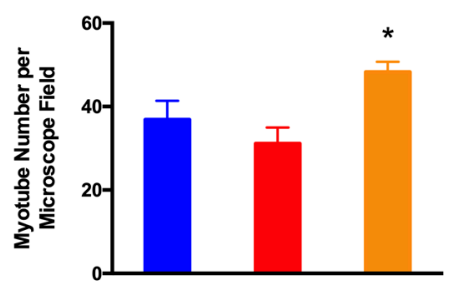

f)

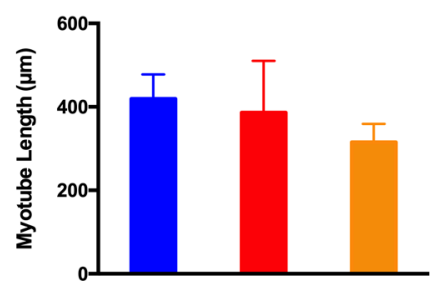

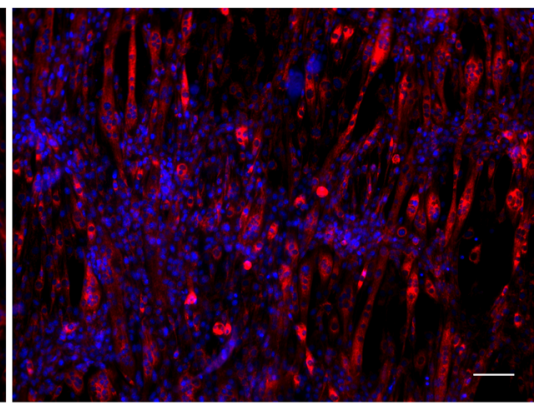

d)

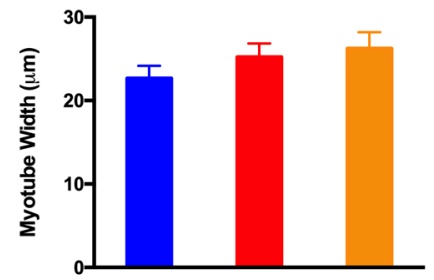

g)

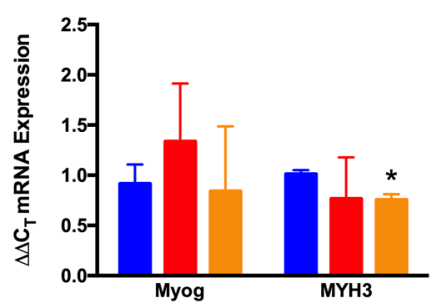

Fig. 4. Long term myogenic perfusion cultures of $\mathrm{C}_{2} \mathrm{C}_{12}$ skeletal muscle cells in monolayer. (a) Live morphological staining of mitochondria (red) and nucleic DNA (blue) of $\mathrm{C}_{2} \mathrm{C}_{12}$ cultured within PA-12 3D printed perfusion system at DM120 h time-points. (b) Nuclei number. (c) Myotube number. (d) Myotube width. (e) Fusion index. (f) Myotube length. (g) Myogenin (Myog) and myosin heavy chain 3 (MYH3) gene expressions at DM120 h time-points. Significantly different from control; * P $\leq 0.05$. Data are derived from $n=3$ experimental repeats and presented \pm standard deviation (SD). Microscopy images $10 \mathrm{x}$ objectives. Scale bars $=100 \mathrm{um}$. 


\subsection{Design and numerical modelling of 3D printed perfusion bioreactor for engineered muscle tissues}

Perfusion systems were adapted to cater for tissue engineered skeletal muscle mould. Designs that are amenable to both modular (Fig. 5a, c) and integrated (Fig. 5b) insertion, as outlined previously (Fig. 1b), were created and used in this work. All systems, 3D printed via LS PA-12, contained comparable internal design specifications to devices earlier described. Tissue engineered moulds are also directly compatible and insertable to all earlier reported perfusion bioreactors regardless of manufacturing process/polymer (SL; ClearFL, PolyJet; VeroClear). To facilitate medium perfusion through the extracellular matrix, no barriers were placed in between the linear flow of medium and the hydrogel (Fig. 5d). Pseudo tendon pins are located perpendicular to the side walls at defined dimensions. ${ }^{36}$ Pins provide resistance to the cell mediated contraction of the type I collagen matrix, resulting in longitudinal tension that provides the mechanical stimuli required to facilitate cell alignment and myoblast fusion. Moulds were designed to include multiple hydrogels within a singular perfusion device in order to yield both histological and molecular analyses from within a single environment.

A steady-state fluid dynamics model was developed to study flow field within the bioreactor and the effect of different flowrates on engineered tissues. Skeletal muscle constructs were modelled as a solid to compute the surrounding fluid flow and to compute shear stress on the tissues. All perfusion system designs elicited a continuous flow through the device with no areas of fluid recirculation or stagnant of media evident. This observation was consistent across all modelled flow rates. i.e. $250 \mu \mathrm{L}$ per h, $500 \mu \mathrm{L}$ per h, $1 \mathrm{~mL}$ per h and 2 $\mathrm{mL}$ per $\mathrm{h}$. Therefore, it can be concluded that within this design, continuous flow regimes enable constant perfusion of the hydrogels, regardless of inlet flow rate (Fig. 5e). Analysis of shear stress on the gel surface of the tissue engineered perfusion systems outlined maximum values of $8.2 \times 10^{-4} \mathrm{~Pa}\left(8.2 \times 10^{-3}\right.$ dynes $\left.\mathrm{cm}^{2}\right)$ at a flowrate of $250 \mu \mathrm{L}$ per h, increasing to $3.3 \times 10^{-3} \mathrm{~Pa}\left(3.3 \times 10^{-2}\right.$ dynes $\left.\mathrm{cm}^{2}\right)$ at a higher flow rate of $2 \mathrm{~mL}$ per $\mathrm{h}$ (Fig. 5f). Fluid velocity plots outline the influence of in situ engineered moulds used to produce the skeletal muscle tissue (Fig. 5g, h). Here, pseudo tendon posts used within this mould partially obstruct the flow, however this was consistent across all flow rates modelled. As increased flow rates did not alter flow profiles within the device and potentially damaging shear stresses induced on the cells is minimum at the lowest modelled flow rate, $250 \mu \mathrm{L}$ per h was selected for the operation of engineered skeletal muscle perfusion cultures. Mass transfer of nutrients and gases from the media to the cells through gel matrix, subsequent biological 
reactions consuming these species and transport of waste from such reactions were not solved in this numerical model. However, it can be envisaged that mass transfer is predominantly controlled by diffusion within the gel rather than fluid convection. Therefore, it is assumed that creeping flow conditions are sufficient to maintain a substantial concentration gradient across the liquid-gel interface for efficient mass transfer. 
a)
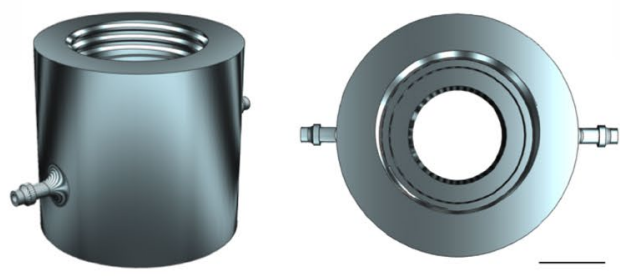

b)
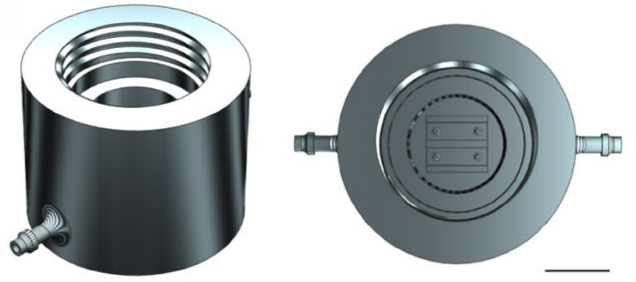

e)

$250 \mu \mathrm{L} / \mathrm{h}$

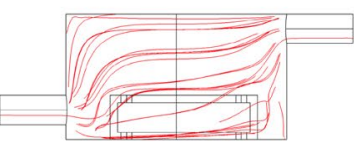

f)

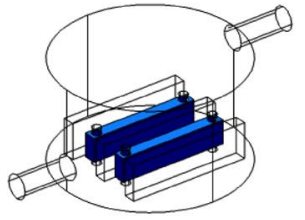

g)

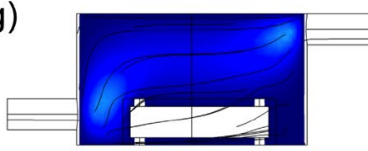

h)

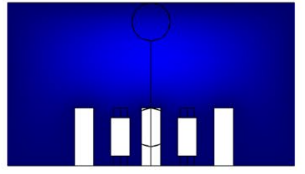

i)

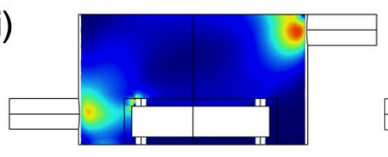

c)

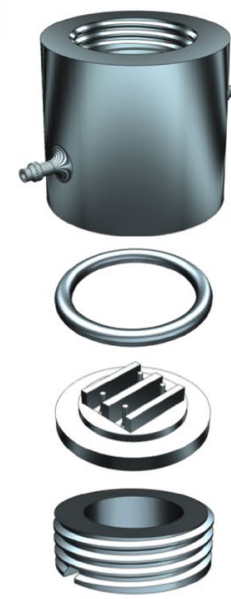

d)

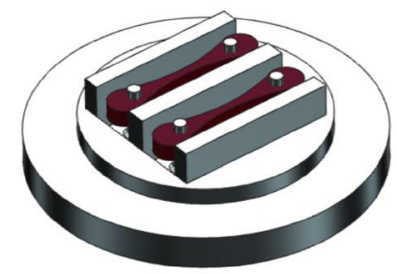

$500 \mu \mathrm{L} / \mathrm{h}$
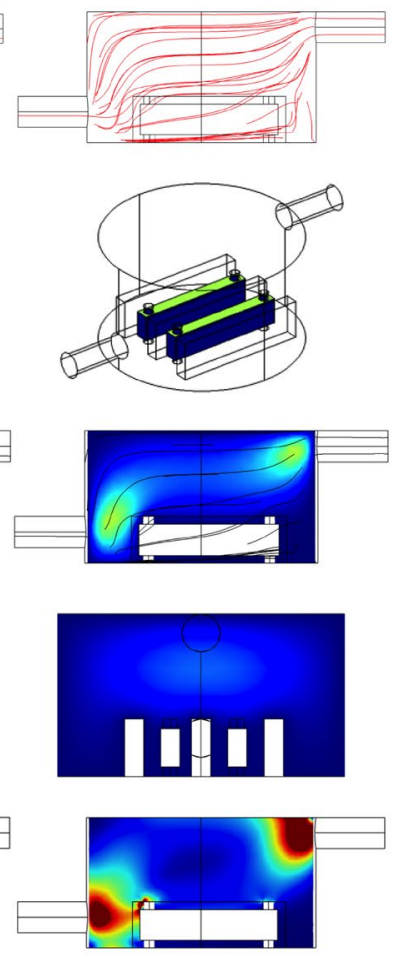

$1 \mathrm{~mL} / \mathrm{h}$
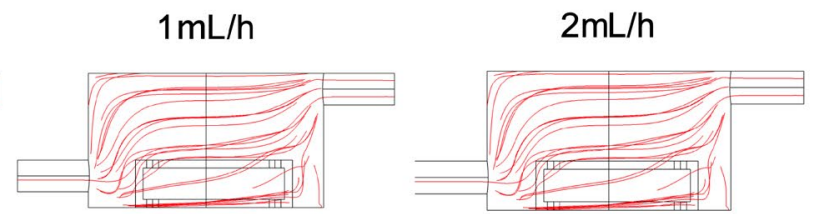
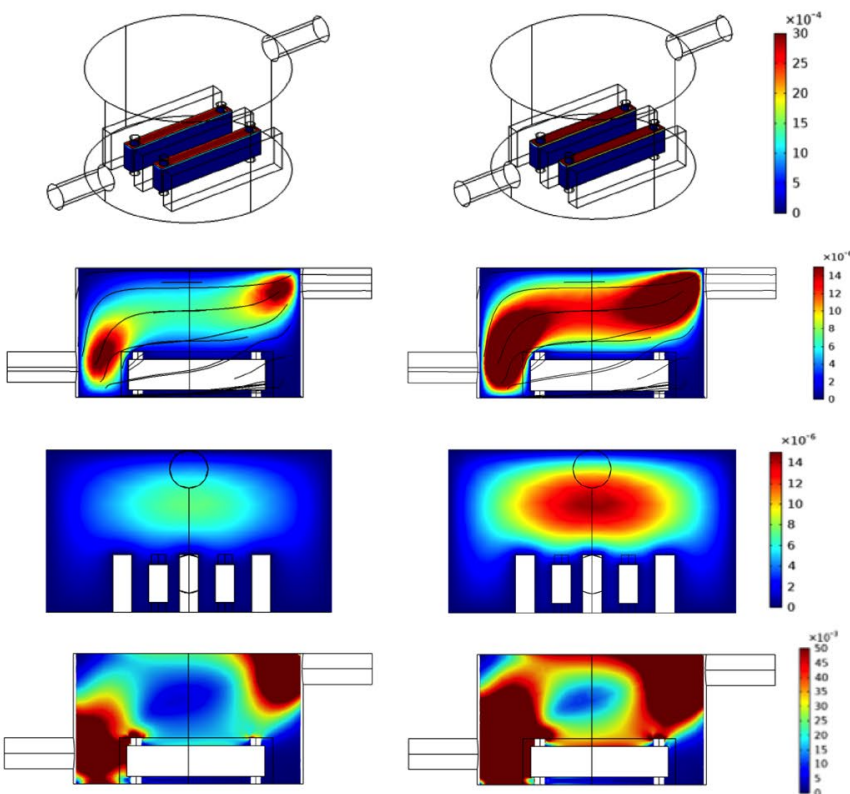
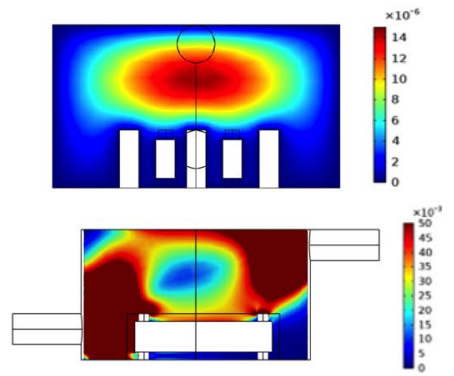

Fig.5. Computer aided design (CAD) models of tissue engineered bioreactors. (a) modular and (b) integrated tissue engineered perfusion systems detailing angled (left) and top (right) views. (c) Schematic of tissue engineered construct integration within perfusion system. (d) Zoom CAD model of tissue engineered mould with exemplar skeletal muscle constructs (red). Results from the numerical simulations at $250 \mu \mathrm{L}, 500 \mu \mathrm{L}, 1 \mathrm{~mL}$ and $2 \mathrm{~mL}$ per h flow rates. (e) Streamlines of fluid flow. (f) Shear stress on the surface of the skeletal muscle construct (Pa). (g) Fluid velocity magnitude on a plane along the centre of a skeletal muscle construct (m/s). (h) Fluid velocity magnitude on a plane across the middle of the skeletal muscle construct $(\mathrm{m} / \mathrm{s})$. (i) Shear rate on a plane along the centre of a skeletal muscle construct $\left(\mathrm{s}^{-1}\right)$. Scale bars $=(\mathrm{a}$ and b) $10 \mathrm{~mm}$ and $(\mathrm{c}) 5 \mathrm{~mm}$. 


\subsection{Myogenic differentiation of tissue engineered skeletal muscle in 3D printed perfusion bioreactor}

Macroscopic analyses (Fig. 6c) of construct deformation demonstrated matrix remodelling predominantly occurred during the first 2 days GM in both continuous perfusion $(250 \mu \mathrm{L}$ per h) and control conditions $(\mathrm{P} \geq$ 0.05). Further statistical deformation was however evident after 14 days culture $(\mathrm{P} \leq 0.0005)$, outlining increased deformation of skeletal muscle hydrogels over time (Fig. 6d). Although no difference was observed after 2 days GM, perfused constructs exhibited statistically increased hydrogel deformation compared to control skeletal muscle constructs after 14 days culture $(\mathrm{P}=0.03)$. Morphological staining (Fig. $6 \mathrm{~b})$ of the actin cytoskeleton, sarcomere protein a-actinin and nuclear DNA outlined comparable phenotypes, with perfusion cultures generating hydrogels of equal width, myotube coverage, myotube density and nuclei number $(\mathrm{P} \geq 0.05)$. In addition to comparable morphological maturation, MuRF1 $(\mathrm{P}=0.003)$, myostatin $(\mathrm{MSTN}, \mathrm{P}=$ 0.001), TNF- $\alpha$ and IL-1 $\beta(\mathrm{P} \leq 0.05)$ mRNA expression was significantly reduced in perfusion conditions, outlining decreased transcription of inflammatory cytokines and negative regulators of skeletal muscle mass in response to 13 days continuous flow. No difference was observed in MAFbx (Fbxo32) or IL-6 gene expression $(\mathrm{P} \geq 0.05)$. Analysis of myosin heavy chain (MYH) transcription outlined comparable expression of embryonic (MYH3), perinatal (MYH8) and type 2X (MYH1) fibres in control conditions. Both type 1 (MYH7) and type 2A (MYH2) heavy chains were significantly reduced in transcription, exhibiting negligible expression compared to MYH3 (P $\leq 0.0005)$. Homogeneous MYH3, MYH8 and MYH1 $(\mathrm{P} \geq 0.05)$ and significant reductions in MYH7 ( $\mathrm{P}=0.013)$ and $\mathrm{MYH} 2(\mathrm{P}=0.011)$ were also evident in perfusion conditions, outlining comparable ratios in heavy chain expression to control constructs. However, when directly compared to control MYH levels, perfusion hydrogels exhibited significantly reduced expression across both embryonic and perinatal myosin heavy chains $(\mathrm{P}=0.008, \mathrm{P}=0.024)$. 


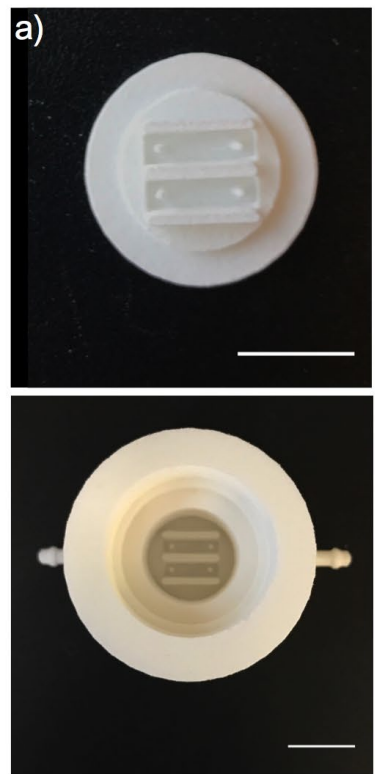

d)

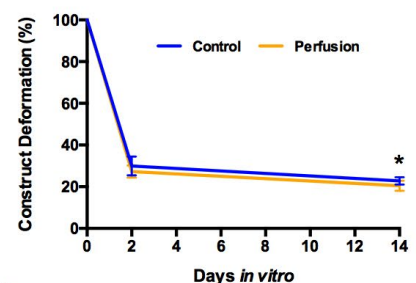

h)

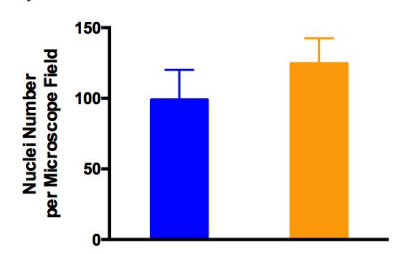

k)

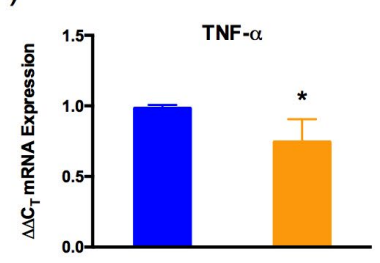

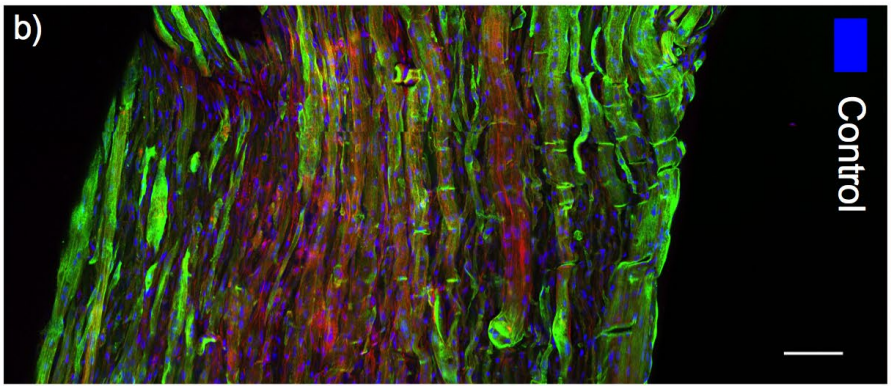
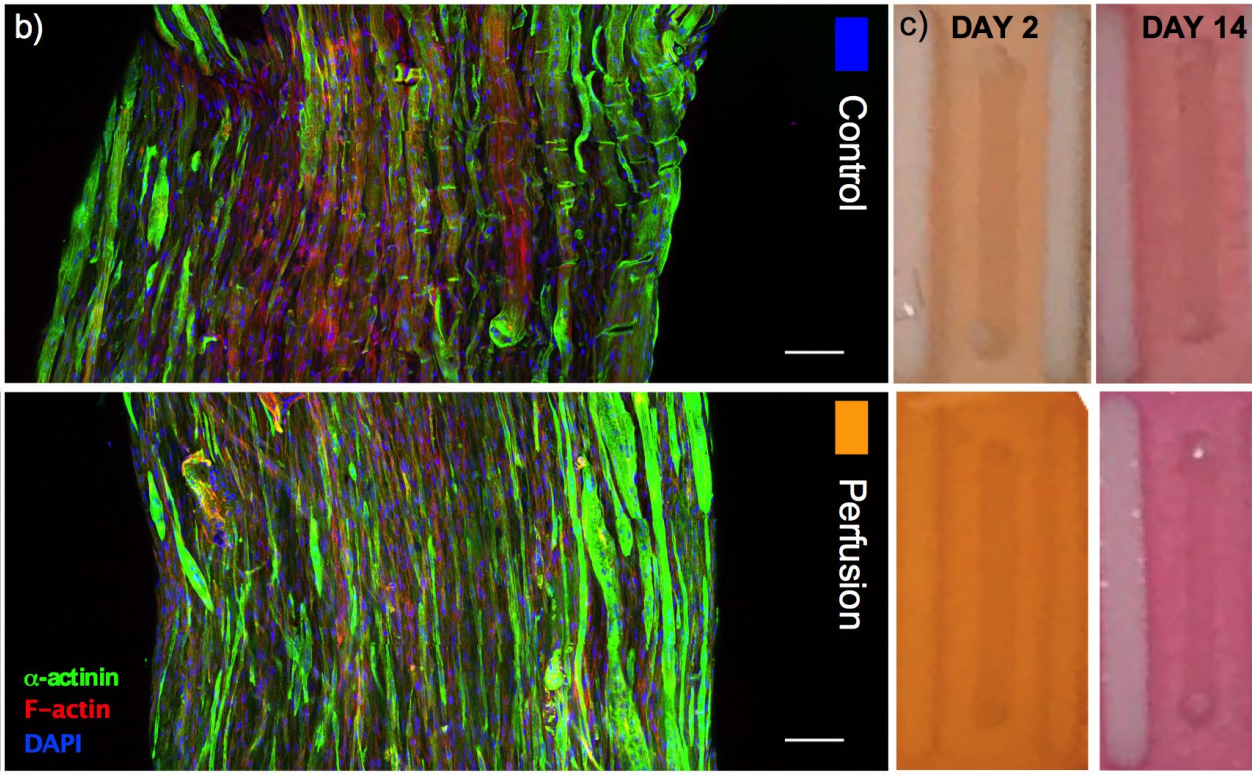

e)

f)
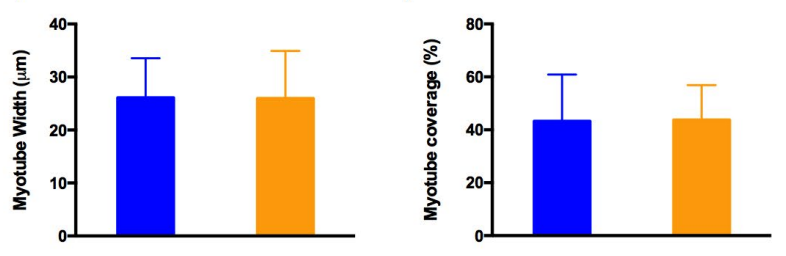

g)
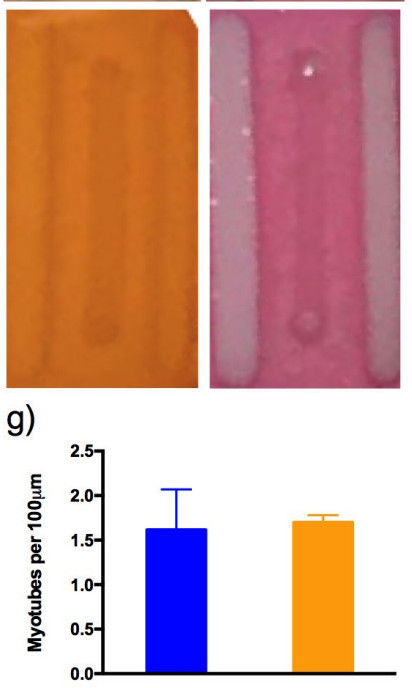

i)
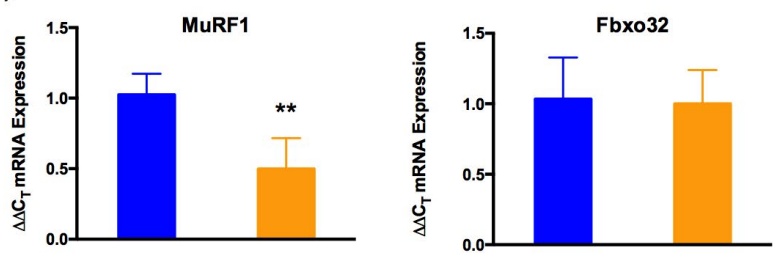

j)

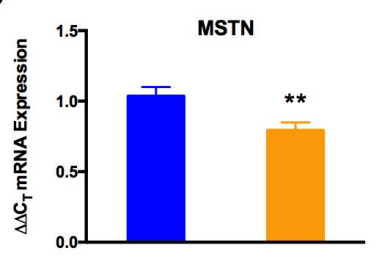

I)
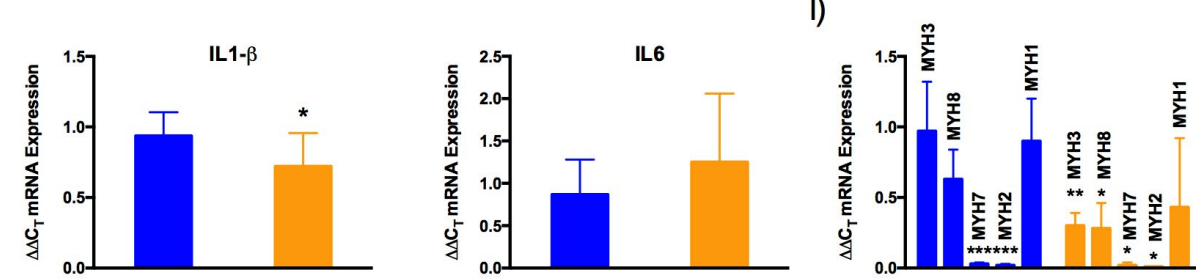

Fig. 6. Myogenic differentiation of murine tissue engineered skeletal muscle in 3D printed perfusion bioreactor. (a) PA-12 control mould (top) and perfusion system (bottom) 3D printed via LS. (b) Morphological staining of sarcomere a-actinin (green), actin cytoskeleton (red) and nucleic DNA (blue) of tissue engineered skeletal muscle hydrogels within 3D printed PA-12 control mould (top) and perfusion systems (bottom) after 14 days culture. (c) Macroscopic deformation of control (top) and perfusion (bottom) skeletal muscle hydrogels after 2- and 14-days culture. (d) Percentage construct deformation. (e) Myotube width. (f) Myotube coverage. (g) Myotube density. (h) Nuclei number. (i) E3 ubiquitin ligases; MuRF1 and Fbxo32 (MAFbx), (j) MSTN (Myostatin) and (k) inflammatory cytokines; TNF- $\alpha$, IL-1 $\beta$ and IL-6 gene expression. (1) Myosin heavy chain gene expression of control and perfusion skeletal muscle constructs. Significantly different; * $\mathrm{P} \leq 0.05,{ }^{* *} \mathrm{P} \leq 0.01, * * * \mathrm{P} \leq 0.0005$. Data are derived from $\mathrm{n}=3$ experimental repeats and presented \pm standard deviation $(\mathrm{SD})$. Control mould and perfusion system scale bars $=10 \mathrm{~mm}$. Fluorescence scale bars $=$ $100 \mu \mathrm{m}$. 


\section{Discussion}

Despite the physiological and technological advantages of perfusion based cell culture systems, ${ }^{58}$ to date no system has been reported that satisfies the in situ phenotypic development of myogenic precursor cells. In addition, the majority of systems created are highly complex in nature and contain a variety of bespoke engineering that limits their wide-ranging reproducibility. This research presents in situ differentiation of skeletal muscle precursor cells in both monolayer and 3D tissue engineered constructs. Designed using CAD software and manufactured via 3D printing techniques, the systems contained within this work are easily reproduced and amenable to cell laden modules that are unlimited in dimension and variety. The functional 3D printed prototypes reported provide a cost effective, adaptable and user-friendly system for the automated generation of large arrays of physiologically representative skeletal muscle tissue for academic research and regenerative medicine applications. Crucially for ease of accessibility, all designs reported in this work are freely available to download at the following URL: https://figshare.com/projects/3D_Printed_Bioreactors/36446.

To aid the translation of the systems created, it was imperative to provide biocompatible systems that are derived from multiple AM processes. To analyse the compatibility of these perfusion environments, myogenic differentiation was undertaken with skeletal muscle cells within static cultures for comparison with classical culture methods. Cells cultured within systems 3D printed via SL and LS displayed homogeneous morphological phenotypes. Both of the 3D printing techniques utilised for the creation of perfusion systems, SL and LS, are processes amenable to the development of complex designs and available as affordable desktop appliances. PolyJet systems tend to be more expensive to purchase and operate. Furthermore, reductions in fusion efficiency, myotube number and length were evident in VeroClear (PolyJet) perfusion systems reproducing previously reported polymer biocompatibility. ${ }^{57}$ However, further reductions were apparent in myoblast fusion when cultured within the perfusion system environment. This is likely a consequence of increased polymer to medium ratio, with incremental chemical leachate within the system resulting in potentiated negative biological effects. Perfusion systems have previously been 3D printed using PolyJet polymer VeroWhite ${ }^{52}$ which reported viable proliferation and maintenance of perfusion cultures. Viable proliferation of skeletal myoblasts was also evident in this work, with the inhibitory effects of VeroClear perfusion system leachate confined to the differentiation phase of myoblast cells. To be robust in their 
translation, systems need support both proliferation and differentiation of precursor cells. As such, it is recommended that Clear-FL and PA-12 systems are the polymers and processes (SL and LS) of choice for 3D printed skeletal muscle perfusion culture.

When seeking to create monolayer perfusion cultures for the real-time optical analysis of myogenic development, it is imperative that sufficient proliferation is maintained to achieve cellular confluence. Skeletal muscle myoblast confluence is essential for myogenic differentiation of this cell type, evidenced by upregulation of myogenic genes when cells are cultured within environments of confined diameters. ${ }^{51}$ Morphological analysis of nuclei number indicated reduced proliferation in perfusion and atmospheric control conditions after $72 \mathrm{~h}$ culture. However, proliferation of perfusion cultures recovered to control levels after 96 $\mathrm{h}$ in GM. This trend was also evident in myogenin and MyoD transcription. Myogenic regulatory factors (MRFs); Myf5, Myf4, MyoD and myogenin, are the key determinants in satellite cell progression and activation during myogenesis. ${ }^{59}$ MyoD induces withdrawal of skeletal muscle satellite cells from the cell cycle prior to terminal commitment. ${ }^{60,61}$ Myogenin expression is indicative of myoblast fusion and occurs at the beginning of myotube fusion. ${ }^{62}$ Comparable levels observed in perfusion conditions to static controls after 96 $\mathrm{h}$ indicates that to achieve physiologically representative myogenic development, perfusion cultures require an additional $24 \mathrm{~h}$ during the growth phase to achieve sufficient cellular confluence to initiate up-regulation of key MRFs.

Implementation of extended growth phases when combined with standard differentiation periods of 5 days produced differentiated perfusion cultures of skeletal muscle myotubes in monolayer. Increases in myotube number were evident within perfusion cultures, with morphological observations indicating myotubes of comparable width but with non-significant reductions in length. No difference was observed in myogenin gene expression outlining equal myoblast fusion into multinucleated myotubes in all conditions. Significant differences were apparent in MYH3 transcription in perfusion conditions compared to positive control, however this effect was not evident compared to static perfusion system controls. This indicates a culture surface material preference of murine skeletal myoblasts, however no effect of 8 days intermittent perfusion on myogenic differentiation. $\mathrm{C}_{2} \mathrm{C}_{12}$ cells have previously been cultured in a microfluidic chip based perfusion system at 5 minute intermittent flows of $0.01 \mu \mathrm{L}$ per minute every 30 minutes. ${ }^{33}$ Although comparable growth rates were observed, perfusion cultures were limited to $24 \mathrm{~h}$. To the authors knowledge this is the first time a 
3D printed perfusion system and protocol has been reported for the in situ myogenic differentiation of skeletal muscle myoblasts. The optical monolayer system reported here holds significant utility in experimental protocols that require real-time visualisation for the study of cellular differentiation. Intermittent perfusion protocols appear to protect myogenic cells from the growth inhibition experienced when removed from atmospheric controlled incubators and cultured within temperature only controlled live imaging systems in chemically buffered environments. The capability of these systems to maintain representative growth and development, without interfering with the system, is essential if aspects of myogenesis are to be studied in real-time and over extended time-periods. Pertinent to this are fluorochromes for live cell imaging. Here, cellular probes, or modified cell lines, that are capable of eliciting acute signals in response to physiological changes such as ion handling ${ }^{3}$, protein phosphorylation or developmental staging would enable the real-time visualisation of key protein upregulation during the myogenic development observed in this work. This system also provides the capability to infuse nutritional and or pharmacological stimulants that produce real-time molecular and morphological data, as well as sacrificial offline genetic and proteomic analysis from an autologous sample population.

Although less receptive to live fluorescent imaging, tissue engineered skeletal muscle hydrogels provide significantly enhanced biomimicry of the in vivo niche..$^{3,5,9-17,35,63-65}$ It is hypothesised that the addition of a dynamic perfusion environment would significantly improve the physiology of these models. ${ }^{58}$ This work observed complete morphological development of tissue engineered skeletal muscle constructs in both control and perfusion (13 days) conditions. Perfusion constructs appeared to exhibit increased matrix remodelling following 13 days exposure to continuous flow rates. This may correlate with non-significant increases in nuclei number per image frame observed in perfusion hydrogels, with increased cell numbers resulting in increases in deformation. Differential transcription of genes that code for E3 ubiquitin ligases; muscle RING finger-containing protein 1 (MuRF1) and muscle atrophy Fbox protein (Fbxo32, MAFbx) were also observed in response to 13 days perfusion. MuRF1 is upregulated in atrophic skeletal muscle ${ }^{66}$ and has been shown to modulate the ubiquitination of the thick filament of sarcomere; myosin heavy chain (MyHC). ${ }^{67,68}$ MAFbx upregulation typically results in muscular atrophy ${ }^{69}$ through downregulation of protein synthesis as an E3 ligase for initiation factor eIF3-f. ${ }^{70-72}$ Here, 50 \% reductions in MuRF1 transcription were evident, however no differences were observed in MAFbx gene expression. Unloading, amino acid deprivation and inflammation have all been linked robustly to increases in MuRF1..$^{73}$ The down regulation of MuRF1 seen in 
perfusion conditions cannot be attributed to a change in external load, ${ }^{74}$ as constructs remain under constant mechanical tension. However, it is important to recognise that although external loads remain constant, changes in biologically generated force via myotube contraction may influence mechanical tension and affect atrophic gene expression. Significant decreases observed in TNF- $\alpha$, IL- $\beta$ and myostatin expression may indicate that such differences are due to a reduction in inflammation within the perfusion environment. TNF$\alpha$ and IL-1 $\beta$ modulate MuRF1 transcription through NF- $\mathrm{KB}$ signalling. ${ }^{75-78}$ Whereas myostatin negatively regulates muscle size via phosphorylation of SMAD2/3 inhibiting AkT, ${ }^{79-81}$ which has been documented to inhibit the transcription of both MuRF1 and MAFbx via the exclusion of (FOXO) family of transcription factors from the nucleus when activated. ${ }^{82-84}$ It is plausible that the continuous replenishment of nutrients and amino acids within perfusion systems elicits an enhanced stability of solutes and as a consequence reduces inflammation within the culture microenvironment. Furthermore, the dynamic nature of perfused environments may improve nutrient delivery and cellular waste removal through the extracellular matrix of tissue engineered muscle, hence reducing atrophic signalling. This is further supported by the MyHC phenotypes, gene expression of MRFs, and morphology observed in perfusion conditions. Both control and perfusion hydrogels displayed preferential transcription of type $2 \mathrm{X}$ fibres compared to type 1 and $2 \mathrm{~A}$, comparable levels of myogenesis (MyoD and myogenin gene expression (Fig. S8)), in addition to morphologically dense constructs of aligned myotubes of comparable widths. Although reductions in MyHC gene transcription were evident in hydrogels exposed to 13 days continuous flow, this coincided with the decreases in MuRF1 observed. This appears to indicate that skeletal muscle constructs cultured within perfusion systems are reaching a reduced basal requirement for expression of MyHC isoform transcripts, due to decreased levels of MuRF1 and subsequent ubiquitination of MyHC protein. ${ }^{67,68}$ Future work should be undertaken at the protein level to investigate the specific mechanisms regulating the changes observed here in mRNA expression. Additionally, mass transfer modelling of nutrients and environmental factors $\left(\mathrm{O}_{2}, \mathrm{pH}\right)$ across varying flow regimes and internal perfusion system designs, that further enhance nutrient delivery and waste solute removal should be examined to identify the optimal conditions for skeletal muscle development.

A number of perfusion based technologies have currently been commercialised to for the screening of drug candidates, ${ }^{85}$ however, no system currently exists for physiologically representative engineered skeletal muscle tissue. 3D printed perfusion systems that cater for the mass generation (96 scaffolds) of human osteoblasts have been reported. ${ }^{53}$ However, the system only appeared amenable to cell types that require mesh-like 3D 
structures, opposed to longitudinal tension required for skeletal muscle architectures. This work provides the initial technology to facilitate the in situ development of skeletal muscle in $3 \mathrm{D}$, allowing the generation and subsequent screening of these tissue constructs en masse. To aid this, both modular and integrated designs reported here facilitate scale up, evidenced via manufactured 6 and 12 well plate perfusion systems (Fig. S9). The use of AM to create the technology presented in this work provides the capability to continually adapt systems to meet the ever changing biological and systematic requirements. Skeletal muscle tissue engineering is a continually evolving field, with necessitated physiological advancements (such as tissue innervation and vascularisation) requiring adaptations to models created. This provides significant advancements in biomimicry that in turn should positively affect the understanding of musculoskeletal pathologies, and regenerative medicine applications. However, such developments also present issues for bespoke systems designed to incorporate previous models derived from unadaptable/restrictive manufacturing processes. AM provides researchers with the capacity to design, iterate and redesign systems with relative ease. Furthermore, the selectivity of designs presented here to be either plate based or modular allows for adaptation of the tissue engineering module without altering the broader system. Together, this should facilitate the seamless integration of new, progressive tissue engineering within perfusion systems for pharmaceutical and academic research.

\section{Conclusion}

This work reports the first system, to the authors' knowledge, that is 3D printed, modular in nature, completely perfused and supports the in situ differentiation of myogenic precursor cells in both monolayer and 3D. In order to fully exploit the beneficial physiological effects of perfusion-based tissue culture, future work should be undertaken in order to further maximise the stability of the culture environment observed. Here, the effect of different rates of continuous flow warrant investigation, specifically with regard to the reductions observed in atrophic, inflammatory and myogenic inhibitory mRNA. With specific regard to the system development for skeletal muscle tissue, incorporating in situ electrical and or mechanical stimulation that elicits muscular contraction would take further steps toward an in vivo physiological environments. ${ }^{58}$ Here, systems that incorporate the ability to place skeletal muscle constructs under a variety of contraction regimes will contribute to the replication of basal and exercised in vivo environments.

\section{List of available designs used in this work}


Monolayer Perfusion System - available at: https://doi.org/10.17028/rd.lboro.6844766.v1.

Modular Tissue Engineered Perfusion System - available at: https://doi.org/10.17028/rd.lboro.6844781.

Integrated Tissue Engineered Perfusion System - available at: https://doi.org/10.17028/rd.lboro.6844799.

Tissue Engineered Skeletal Muscle Mould - available at: https://doi.org/10.17028/rd.lboro.6834488.

Modular 6-well plate Bioreactor - available at: https://doi.org/10.17028/rd.lboro.6844802.

Integrated 12-well plate Bioreactor - available at: https://doi.org/10.17028/rd.lboro.6844844.

Screw Thread - available at: https://doi.org/10.17028/rd.lboro.6844772.

O-ring Mould - available at: https://doi.org/10.17028/rd.lboro.6844769.

\section{Acknowledgements}

This research was undertaken within a mini centre for doctoral training (CDT) funded by Loughborough University. This work was supported in part by EPSRC Grant REF: EP/L02067X/2. Authors acknowledge that part of the introductory text from this article is also used to introduce the Open Access published designs listed in this work on figshare at the following URL: https://figshare.com/projects/3D_Printed_Bioreactors/36446.

\section{Supplementary Information}

This file includes:

1. Tables S1 - Primers utilised for the examination of target mRNA.

2. Fig. S1 - Technical drawings of perfusion system detailed (a) top, (b) side and (c) end views of device.

3. Fig. S2. Technical drawings of perfusion system with integrated tissue engineered scaffold.

4. Fig. S3. Technical drawings of tissue engineered scaffold module.

5. Fig. S4. Clear-FL perfusion system inter-use leachate protocol.

6. Fig. S5. Clear-FL perfusion system leachate protocol optimisation.

7. Fig. S6. Morphological staining of F-actin (red) and nuclei (blue) in positive control condition.

8. Fig. S7. Clear-FL perfusion system leachate protocol optimisation via HPLC.

9. Fig. S8. Comparable myogenic gene expression of (a) MyoD and (b) Myogenin (myog) within control and perfused 3D tissue engineered skeletal muscle constructs.

10. Fig. S9. Designs for plate-based bioreactors (6-well and 12-well), allowing experimental scale up that contain parallel arrays of scaled perfusion systems within a singular device. 


\section{References}

(1) Martin, N. R. .; Turner, M. .; Farrington, R.; Player, D. .; Lewis, M. . Leucine Elicits Myotube Hypertrophy and Enhances Maximal Contractile Force in Tissue Engineered Skeletal Muscle in Vitro. J. Cell. Physiol. 2017. https://doi.org/10.1002/jcp.25960.

(2) Agrawal, G.; Aung, A.; Varghese, S. Skeletal Muscle-on-a-Chip: An in Vitro Model to Evaluate Tissue Formation and Injury. Lab Chip 2017. https://doi.org/10.1039/C7LC00512A.

(3) Madden, L.; Juhas, M.; Kraus, W. E.; Truskey, G. A.; Bursac, N. Bioengineered Human Myobundles Mimic Clinical Responses of Skeletal Muscle to Drugs. Elife 2015, 4, e04885. https://doi.org/10.7554/eLife.04885.

(4) Kasper, A. M.; Turner, D. C.; Martin, N. R. W.; Sharples, A. P. Mimicking Exercise in ThreeDimensional Bioengineered Skeletal Muscle to Investigate Cellular and Molecular Mechanisms of Physiological Adaptation. J. Cell. Physiol. 2017. https://doi.org/10.1002/jcp.25840.

(5) Sharples, A. P.; Player, D. J.; Martin, N. R. W.; Mudera, V.; Stewart, C. E.; Lewis, M. P. Modelling in Vivo Skeletal Muscle Ageing in Vitro Using Three-Dimensional Bioengineered Constructs. Aging Cell 2012, 11 (6), 986-995. https://doi.org/10.1111/j.1474-9726.2012.00869.x.

(6) Sharples, A. P.; Al-Shanti, N.; Stewart, C. E. C2 and C2C12 Murine Skeletal Myoblast Models of Atrophic and Hypertrophic Potential: Relevance to Disease and Ageing? J. Cell. Physiol. 2010, 225 (1), 240-250. https://doi.org/10.1002/jcp.22252.

(7) Martin, N. R. W.; Aguilar-Agon, K.; Robinson, G. P.; Player, D. J.; Turner, M. C.; Myers, S. D.; Lewis, M. P. Hypoxia Impairs Muscle Function and Reduces Myotube Size in Tissue Engineered Skeletal Muscle. J. Cell. Biochem. 2017. https://doi.org/10.1002/jcb.25982.

(8) Vanderburgh, J.; Sterling, J. a.; Guelcher, S. a. 3D Printing of Tissue Engineered Constructs for In Vitro Modeling of Disease Progression and Drug Screening. Ann. Biomed. Eng. 2017, 45 (1), 164 179. https://doi.org/10.1007/s10439-016-1640-4.

(9) Juhas, M.; Engelmayr, G. C.; Fontanella, A. N.; Palmer, G. M.; Bursac, N. Biomimetic Engineered Muscle with Capacity for Vascular Integration and Functional Maturation in Vivo. Proc. Natl. Acad. Sci. U. S. A. 2014, 111 (15), 5508-5513. https://doi.org/10.1073/pnas.1402723111. 
(10) Bian, W.; Bursac, N. Tissue Engineering of Functional Skeletal Muscle: Challenges and Recent Advances. IEEE Eng. Med. Biol. Mag. 2008, 27 (5), 109-113.

https://doi.org/10.1109/MEMB.2008.928460.

(11) Hinds, S.; Bian, W.; Dennis, R. G.; Bursac, N. The Role of Extracellular Matrix Composition in Structure and Function of Bioengineered Skeletal Muscle. Biomaterials 2011, 32 (14), 3575-3583. https://doi.org/10.1016/j.biomaterials.2011.01.062.

(12) Smith, A. S. T.; Passey, S.; Greensmith, L.; Mudera, V.; Lewis, M. P. Characterization and Optimization of a Simple, Repeatable System for the Long Term in Vitro Culture of Aligned Myotubes in 3D. J. Cell. Biochem. 2012, 113 (3), 1044-1053. https://doi.org/10.1002/jcb.23437.

(13) Cheng, C. S.; Davis, B. N. J.; Madden, L.; Bursac, N.; Truskey, G. A. Physiology and Metabolism of Tissue-Engineered Skeletal Muscle. Exp. Biol. Med. (Maywood). 2014, 239 (9), 1203-1214. https://doi.org/10.1177/1535370214538589.

(14) Rao, L.; Qian, Y.; Khodabukus, A.; Ribar, T.; Bursac, N. Engineering Human Pluripotent Stem Cells into a Functional Skeletal Muscle Tissue. Nat. Commun. 2018, 9 (1), 126. https://doi.org/10.1038/s41467-017-02636-4.

(15) Player, D. J.; Martin, N. R. W.; Passey, S. L.; Sharples, a P.; Mudera, V.; Lewis, M. P. Acute Mechanical Overload Increases IGF-I and MMP-9 mRNA in 3D Tissue-Engineered Skeletal Muscle. Biotechnol. Lett. 2014, 36 (5), 1113-1124. https://doi.org/10.1007/s10529-014-1464-y.

(16) Martin, N. R. W.; Passey, S. L.; Player, D. J.; Khodabukus, A.; Ferguson, R. A.; Sharples, A. P.; Mudera, V.; Baar, K.; Lewis, M. P. Factors Affecting the Structure and Maturation of Human Tissue Engineered Skeletal Muscle. Biomaterials 2013, 34 (23), 5759-5765. https://doi.org/10.1016/j.biomaterials.2013.04.002.

(17) Cheema, U.; Yang, S.-Y.; Mudera, V.; Goldspink, G. G.; Brown, R. a. 3-D in Vitro Model of Early Skeletal Muscle Development. Cell Motil. Cytoskeleton 2003, 54 (3), 226-236. https://doi.org/10.1002/cm.10095.

(18) Smith, A. S. T.; Passey, S. L.; Martin, N. R. W.; Player, D. J.; Mudera, V.; Greensmith, L.; Lewis, M. P. Creating Interactions between Tissue-Engineered Skeletal Muscle and the Peripheral Nervous 
System. Cells Tissues Organs 2016, 202 (3-4), 143-158. https://doi.org/10.1159/000443634.

(19) Martin, N. R. W.; Passey, S. L.; Player, D. J.; Mudera, V.; Baar, K.; Greensmith, L.; Lewis, M. P. Neuromuscular Junction Formation in Tissue-Engineered Skeletal Muscle Augments Contractile Function and Improves Cytoskeletal Organization. Tissue Eng. Part A 2015, 21 (19-20), 2595-2604. https://doi.org/10.1089/ten.tea.2015.0146.

(20) Cheng, M.; Moretti, M.; Engelmayr, G. C.; Freed, L. E. Insulin-like Growth Factor-I and Slow, BiDirectional Perfusion Enhance the Formation of Tissue-Engineered Cardiac Grafts. Tissue Eng. Part A 2009, 15 (3), 645-653. https://doi.org/10.1089/ten.tea.2008.0077.

(21) Jaccard, N.; Macown, R. J.; Super, A.; Griffin, L. D.; Veraitch, F. S.; Szita, N. Automated and Online Characterization of Adherent Cell Culture Growth in a Microfabricated Bioreactor. J. Lab. Autom. 2014, 19 (5), 437-443. https://doi.org/10.1177/2211068214529288.

(22) Abeille, F.; Mittler, F.; Obeid, P.; Huet, M.; Kermarrec, F.; Dolega, M. E.; Navarro, F.; Pouteau, P.; Icard, B.; Gidrol, X.; et al. Continuous Microcarrier-Based Cell Culture in a Benchtop Microfluidic Bioreactor. Lab Chip 2014, 14 (18), 3435-3652. https://doi.org/10.1039/C4LC00570H.

(23) Bulnes-Abundis, D.; Carrillo-Cocom, L. M.; Aráiz-Hernández, D.; García-Ulloa, A.; GranadosPastor, M.; Sánchez-Arreola, P. B.; Murugappan, G.; Alvarez, M. M. A Simple Eccentric Stirred Tank Mini-Bioreactor: Mixing Characterization and Mammalian Cell Culture Experiments. Biotechnol. Bioeng. 2013, 110 (4), 1106-1118. https://doi.org/10.1002/bit.24780.

(24) Tilles, A. W.; Baskaran, H.; Roy, P.; Yarmush, M. L.; Toner, M. Effects of Oxygenation and Flow on the Viability and Function of Rat Hepatocytes Cocultured in a Microchannel Flat-Plate Bioreactor. Biotechnol. Bioeng. 2001, 73 (5), 379-389. https://doi.org/10.1002/bit.1071.

(25) Walzik, M. P.; Vollmar, V.; Lachnit, T.; Dietz, H.; Haug, S.; Bachmann, H.; Fath, M.; Aschenbrenner, D.; Abolpour Mofrad, S.; Friedrich, O.; et al. A Portable Low-Cost Long-Term LiveCell Imaging Platform for Biomedical Research and Education. Biosens. Bioelectron. 2015, 64, 639649. https://doi.org/10.1016/j.bios.2014.09.061.

(26) Ratcliffe, E.; Glen, K. E.; Workman, V. L.; Stacey, a. J.; Thomas, R. J. A Novel Automated Bioreactor for Scalable Process Optimisation of Haematopoietic Stem Cell Culture. J. Biotechnol. 
2012, 161 (3), 387-390. https://doi.org/10.1016/j.jbiotec.2012.06.025.

(27) Killian, N. J.; Vernekar, V. N.; Potter, S. M.; Vukasinovic, J. A Device for Long-Term Perfusion, Imaging, and Electrical Interfacing of Brain Tissue In Vitro. Front. Neurosci. 2016, 10, 135. https://doi.org/10.3389/fnins.2016.00135.

(28) Dahlin, R. L.; Meretoja, V. V.; Ni, M.; Kasper, F. K.; Mikos, A. G. Design of a High-Throughput Flow Perfusion Bioreactor System for Tissue Engineering. Tissue Eng. Part C. Methods 2012, 18 (10), 817-820. https://doi.org/10.1089/ten.tec.2012.0037.

(29) Schmelzer, E.; Finoli, A.; Nettleship, I.; Gerlach, J. C. J. C. J. C. J. C. Long-Term Three-Dimensional Perfusion Culture of Human Adult Bone Marrow Mononuclear Cells in Bioreactors. Biotechnol. Bioeng. 2015, 112 (4), 801-810. https://doi.org/10.1002/bit.25485.

(30) Shansky, J.; Creswick, B.; Lee, P.; Wang, X.; Vandenburgh, H. Paracrine Release of Insulin-like Growth Factor 1 from a Bioengineered Tissue Stimulates Skeletal Muscle Growth in Vitro. Tissue Eng. 2006, 12 (7), 1833-1841. https://doi.org/10.1089/ten.2006.12.1833.

(31) Maidhof, R.; Marsano, A.; Lee, E. J.; Vunjak-Novakovic, G. Perfusion Seeding of Channeled Elastomeric Scaffolds with Myocytes and Endothelial Cells for Cardiac Tissue Engineering. Biotechnol. Prog. 2010, 26 (2), 565-572. https://doi.org/10.1002/btpr.337.

(32) Cerino, G.; Gaudiello, E.; Grussenmeyer, T.; Melly, L.; Massai, D.; Banfi, A.; Martin, I.; Eckstein, F.; Grapow, M.; Marsano, A. Three Dimensional Multi-Cellular Muscle-like Tissue Engineering in Perfusion-Based Bioreactors. Biotechnol. Bioeng. 2016, 113 (1), 226-236. https://doi.org/10.1002/bit.25688.

(33) Kurth, F.; Franco-Obregón, A.; Bärtschi, C. A.; Dittrich, P. S. An Adaptable Stage Perfusion Incubator for the Controlled Cultivation of C2C12 Myoblasts. Analyst 2015, 140 (1), 127-133. https://doi.org/10.1039/c4an01758g.

(34) Chromiak, J. A.; Shansky, J.; Perrone, C.; Vandenburgh, H. H. Bioreactor Perfusion System for the Long-Term Maintenance of Tissue-Engineered Skeletal Muscle Organoids. In Vitro Cell. Dev. Biol. Anim. 1998, 34 (9), 694-703. https://doi.org/10.1007/s11626-998-0065-2.

(35) Vandenburgh, H.; Shansky, J.; Benesch-Lee, F.; Barbata, V.; Reid, J.; Thorrez, L.; Valentini, R.; 
Crawford, G. Drug-Screening Platform Based on the Contractility of Tissue-Engineered Muscle. Muscle and Nerve 2008, 37 (4), 438-447. https://doi.org/10.1002/mus.20931.

(36) Capel, A. J.; Rimington, R. P.; Fleming, J. W.; Player, D. J.; Baker, L. A.; Turner, M. C.; Jones, J. M.; Martin, N. R. W.; Ferguson, R. A.; Mudera, V. C.; et al. Scalable 3D Printed Molds for Human Tissue Engineered Skeletal Muscle. Front. Bioeng. Biotechnol. 2019, 7 (February), 1-13. https://doi.org/10.3389/fbioe.2019.00020.

(37) Vandenburgh, H. High-Content Drug Screening with Engineered Musculoskeletal Tissues. Tissue Eng. Part B. Rev. 2010, 16 (1), 55-64. https://doi.org/10.1089/ten.TEB.2009.0445.

(38) Hung, P. J.; Lee, P. J.; Sabounchi, P.; Lin, R.; Lee, L. P. Continuous Perfusion Microfluidic Cell Culture Array for High-Throughput Cell-Based Assays. Biotechnol. Bioeng. 2005, 89 (1), 1-8. https://doi.org/10.1002/bit.20289.

(39) Lei, K. F.; Wu, M.-H.; Hsu, C.-W.; Chen, Y.-D. Real-Time and Non-Invasive Impedimetric Monitoring of Cell Proliferation and Chemosensitivity in a Perfusion 3D Cell Culture Microfluidic Chip. Biosens. Bioelectron. 2014, 51, 16-21. https://doi.org/10.1016/j.bios.2013.07.031.

(40) Tong, Z.; Seira, O.; Casas, C.; Reginensi, D.; Homs-Corbera, A.; Samitier, J.; Del Río, J. A. Engineering a Functional Neuro-Muscular Junction Model in a Chip. RSC Adv. 2014, 4 (97), 5478854797. https://doi.org/10.1039/C4RA10219C.

(41) de Souza Leite, F.; Minozzo, F. C.; Altman, D.; Rassier, D. E. Microfluidic Perfusion Shows Intersarcomere Dynamics within Single Skeletal Muscle Myofibrils. Proc. Natl. Acad. Sci. 2017, 201700615. https://doi.org/10.1073/pnas.1700615114.

(42) Kitson, P. J.; Rosnes, M. H.; Sans, V.; Dragone, V.; Cronin, L. Configurable 3D-Printed Millifluidic and Microfluidic "lab on a Chip" Reactionware Devices. Lab Chip 2012, 12 (18), 3267. https://doi.org/10.1039/c2lc40761b.

(43) Gross, B. C.; Anderson, K. B.; Meisel, J. E.; McNitt, M. I.; Spence, D. M. Polymer Coatings in 3DPrinted Fluidic Device Channels for Improved Cellular Adherence Prior to Electrical Lysis. Anal. Chem. 2015, 87 (12), 6335-6341. https://doi.org/10.1021/acs.analchem.5b01202.

(44) Lockwood, S. Y.; Meisel, J. E.; Monsma, F. J.; Spence, D. M. A Diffusion-Based and Dynamic 3D- 
Printed Device That Enables Parallel in Vitro Pharmacokinetic Profiling of Molecules. Anal. Chem. 2016, 88 (3), 1864-1870. https://doi.org/10.1021/acs.analchem.5b04270.

(45) Capel, A. J.; Edmondson, S.; Christie, S. D. R.; Goodridge, R. D.; Bibb, R. J.; Thurstans, M. Design and Additive Manufacture for Flow Chemistry. Lab Chip 2013, 13 (23), 4583-4590. https://doi.org/10.1039/c31c50844g.

(46) Capel, A. J.; Wright, A.; Harding, M. J.; Weaver, G. W.; Li, Y.; Harris, R. A.; Edmondson, S.; Goodridge, R. D.; Christie, S. D. R. 3D Printed Fluidics with Embedded Analytic Functionality for Automated Reaction Optimisation. Beilstein J. Org. Chem. 2017, 13, 111-119. https://doi.org/10.3762/bjoc.13.14.

(47) Monaghan, T.; Harding, M. J.; Harris, R. A.; Friel, R. J.; Christie, S. D. R. Customisable 3D Printed Microfluidics for Integrated Analysis and Optimisation. Lab Chip 2016, 16 (17), 3362-3373. https://doi.org/10.1039/C6LC00562D.

(48) Johnson, B. N.; Lancaster, K. Z.; Hogue, I. B.; Meng, F.; Kong, Y. L.; Enquist, L. W.; McAlpine, M. C. 3D Printed Nervous System on a Chip. Lab Chip 2016, 16 (8), 1393-1400. https://doi.org/10.1039/C5LC01270H.

(49) Park, J.; Wetzel, I.; Dréau, D.; Cho, H. 3D Miniaturization of Human Organs for Drug Discovery. Adv. Healthc. Mater. 2017, 1700551, 1700551. https://doi.org/10.1002/adhm.201700551.

(50) Peris, E.; Okafor, O.; Kulcinskaja, E.; Goodridge, R.; Luis, S. V.; Garcia-Verdugo, E.; O’Reilly, E.; Sans, V. Tuneable 3D Printed Enzymatic Reactors for Continuous-Flow Biotransformations. Green Chem. 2017. https://doi.org/10.1039/C7GC02421E.

(51) Rimington, R. P.; Capel, A. J.; Christie, S. D. R.; Lewis, M. P. Biocompatible 3D Printed Polymers via Fused Deposition Modelling Direct C2C12 Cellular Phenotype in Vitro. Lab Chip 2017, 17 (17), 2982-2993. https://doi.org/10.1039/c7lc00577f.

(52) Balakrishnan, S.; Suma, M. S.; Raju, S. R.; Bhargav, S. D. B.; Arunima, S.; Das, S.; Ananthasuresh, G. K. A Scalable Perfusion Culture System with Miniature Peristaltic Pumps for Live-Cell Imaging Assays with Provision for Microfabricated Scaffolds. Biores. Open Access 2015, 4 (1), 343-357. https://doi.org/10.1089/biores.2015.0024. 
(53) Costa, P. F.; Hutmacher, D. W.; Theodoropoulos, C.; Gomes, M. E.; Reis, R. L.; Vaquette, C. Additively Manufactured Device for Dynamic Culture of Large Arrays of 3D Tissue Engineered Constructs. Adv. Healthc. Mater. 2015, 4 (6), 864-873. https://doi.org/10.1002/adhm.201400591.

(54) Schindelin, J.; Arganda-Carreras, I.; Frise, E.; Kaynig, V.; Longair, M.; Pietzsch, T.; Preibisch, S.; Rueden, C.; Saalfeld, S.; Schmid, B.; et al. Fiji: An Open-Source Platform for Biological-Image Analysis. Nat. Methods 2012, 9 (7), 676-682. https://doi.org/10.1038/nmeth.2019.

(55) Livak, K. J.; Schmittgen, T. D. Analysis of Relative Gene Expression Data Using Real-Time Quantitative PCR and the 2(-Delta Delta C(T)) Method. Methods 2001, 25 (4), 402-408. https://doi.org/10.1006/meth.2001.1262.

(56) Coletti, F.; Macchietto, S.; Nlvassore, N. Mathematical Modelling of Three-Dimensional Cell Cultures in Perfusion Bioreactors. Part II. In Computer Aided Chemical Engineering; 2006; Vol. 21, pp 1699-1704. https://doi.org/10.1016/S1570-7946(06)80292-0.

(57) Rimington, R. P.; Capel, A. J.; Player, D. J.; Bibb, R. J.; Christie, S. D. R.; Lewis, M. P. Feasibility and Biocompatibility of 3D-Printed Photopolymerized and Laser Sintered Polymers for Neuronal, Myogenic, and Hepatic Cell Types. Macromol. Biosci. 2018, 1800113, e1800113. https://doi.org/10.1002/mabi.201800113.

(58) Rangarajan, S.; Madden, L.; Bursac, N. Use of Flow, Electrical, and Mechanical Stimulation to Promote Engineering of Striated Muscles. Ann. Biomed. Eng. 2014, 42 (7), 1391-1405. https://doi.org/10.1007/s10439-013-0966-4.

(59) Zanou, N.; Gailly, P. Skeletal Muscle Hypertrophy and Regeneration: Interplay between the Myogenic Regulatory Factors (MRFs) and Insulin-like Growth Factors (IGFs) Pathways. Cell. Mol. Life Sci. 2013, 70 (21), 4117-4130. https://doi.org/10.1007/s00018-013-1330-4.

(60) Wilson, E. M.; Rotwein, P. Control of MyoD Function during Initiation of Muscle Differentiation by an Autocrine Signaling Pathway Activated by Insulin-like Growth Factor-II. J. Biol. Chem. 2006, 281 (40), 29962-29971. https://doi.org/10.1074/jbc.M605445200.

(61) Halevy, O.; Novitch, B. G.; Spicer, D. B.; Skapek, S. X.; Rhee, J.; Hannon, G. J.; Beach, D.; Lassar, A. B. Correlation of Terminal Cell-Cycle Arrest of Skeletal-Muscle with Induction of p21 by myoD. 
Science (80-. ). 1995, 267 (February), 1018-1021.

(62) Hasty, P.; Bradley, A.; Morris, J. H.; Edmondson, D. G.; Venuti, J. M.; Olson, E. N.; Klein, W. H. Muscle Deficiency and Neonatal Death in Mice with a Targeted Mutation in the Myogenin Gene. Nature 1993, 364 (6437), 501-506. https://doi.org/10.1038/364501a0.

(63) Guo, X.; Greene, K.; Akanda, N.; Smith, A.; Stancescu, M.; Lambert, S.; Vandenburgh, H.; Hickman, J. In Vitro Differentiation of Functional Human Skeletal Myotubes in a Defined System. Biomater. Sci. 2014, 2 (1), 131-138. https://doi.org/10.1039/C3BM60166H.

(64) Powell, C. A.; Smiley, B. L.; Mills, J.; Vandenburgh, H. H. Mechanical Stimulation Improves TissueEngineered Human Skeletal Muscle. Am. J. Physiol. Cell Physiol. 2002, 283 (5), C1557-65. https://doi.org/10.1152/ajpcell.00595.2001.

(65) Brady, M. A.; Lewis, M. P.; Mudera, V. Synergy between Myogenic and Non-Myogenic Cells in a 3D Tissue-Engineered Craniofacial Skeletal Muscle Construct. J. Tissue Eng. Regen. Med. 2008, 2 (7), 408-417. https://doi.org/10.1002/term.112.

(66) Bodine, S. C.; Lai, V. K.; Nunez, L.; Clarke, B. A. Skeletal Muscle Atrophy Identification of Ubiquitin Ligases Required for Skeletal Muscle Atrophy. Science (80-. ). 2007, 1704 (2001), $1704-$ 1708. https://doi.org/10.1126/science.1065874.

(67) Cohen, S.; Brault, J. J.; Gygi, S. P.; Glass, D. J.; Valenzuela, D. M.; Gartner, C.; Latres, E.; Goldberg, A. L. During Muscle Atrophy, Thick, but Not Thin, Filament Components Are Degraded by MuRF1Dependent Ubiquitylation. J. Cell Biol. 2009, 185 (6), 1083-1095. https://doi.org/10.1083/jcb.200901052.

(68) Clarke, B. A.; Drujan, D.; Willis, M. S.; Murphy, L. O.; Corpina, R. A.; Burova, E.; Rakhilin, S. V.; Stitt, T. N.; Patterson, C.; Latres, E.; et al. The E3 Ligase MuRF1 Degrades Myosin Heavy Chain Protein in Dexamethasone-Treated Skeletal Muscle. Cell Metab. 2007, 6 (5), 376-385. https://doi.org/10.1016/j.cmet.2007.09.009.

(69) Gomes, M. D.; Lecker, S. H.; Jagoe, R. T.; Navon, A.; Goldberg, A. L. Atrogin-1, a Muscle-Specific F-Box Protein Highly Expressed during Muscle Atrophy. Proc. Natl. Acad. Sci. U. S. A. 2001, 98 (25), 14440-14445. https://doi.org/10.1073/pnas.251541198. 
(70) Li, H.-H.; Willis, M. S.; Lockyer, P.; Miller, N.; McDonough, H.; Glass, D. J.; Patterson, C. Atrogin1 Inhibits Akt-Dependent Cardiac Hypertrophy in Mice via Ubiquitin-Dependent Coactivation of Forkhead Proteins. J. Clin. Invest. 2007, 117 (11), 3211-3223. https://doi.org/10.1172/JCI31757.

(71) Csibi, A.; Leibovitch, M. P.; Cornille, K.; Tintignac, L. A.; Leibovitch, S. A. MAFbx/Atrogin-1 Controls the Activity of the Initiation Factor eIF3-Fin Skeletal Muscle Atrophy by Targeting Multiple C-Terminal Lysines. J. Biol. Chem. 2009, 284 (7), 4413-4421. https://doi.org/10.1074/jbc.M807641200.

(72) Lagirand-Cantaloube, J.; Offner, N.; Csibi, A.; Leibovitch, M. P.; Batonnet-Pichon, S.; Tintignac, L. A.; Segura, C. T.; Leibovitch, S. A. The Initiation Factor eIF3-F Is a Major Target for Atrogin1/MAFbx Function in Skeletal Muscle Atrophy. EMBO J. 2008, 27 (8), 1266-1276. https://doi.org/10.1038/emboj.2008.52.

(73) Egerman, M. a; Glass, D. J. Signaling Pathways Controlling Skeletal Muscle Mass. Crit. Rev. Biochem. Mol. Biol. 2014, 49 (1), 59-68. https://doi.org/10.3109/10409238.2013.857291.

(74) NIKAWA, T.; ISHIDOH, K.; HIRASAKA, K.; ISHIHARA, I.; IKEMOTO, M.; KANO, M.; KOMINAMI, E.; NONAKA, I.; OGAWA, T.; ADAMS, G. R.; et al. Skeletal Muscle Gene Expression in Space-Flown Rats. FASEB J. 2004, 18 (3), 522-524. https://doi.org/10.1096/fj.030419fje.

(75) Li, H.; Malhotra, S.; Kumar, A. Nuclear Factor-Kappa B Signaling in Skeletal Muscle Atrophy. $J$. Mol. Med. (Berl). 2008, 86 (10), 1113-1126. https://doi.org/10.1007/s00109-008-0373-8.

(76) Langen, R. C.; Schols, a M.; Kelders, M. C.; Wouters, E. F.; Janssen-Heininger, Y. M. Inflammatory Cytokines Inhibit Myogenic Differentiation through Activation of Nuclear Factor-kappaB. FASEB J. 2001, 15, 1169-1180. https://doi.org/10.1096/fj.00-0463.

(77) Cai, D.; Frantz, J. D.; Tawa, N. E.; Melendez, P. A.; Oh, B. C.; Lidov, H. G. W.; Hasselgren, P. O.; Frontera, W. R.; Lee, J.; Glass, D. J.; et al. IKK $\beta / N F-\kappa B$ Activation Causes Severe Muscle Wasting in Mice. Cell 2004, 119 (2), 285-298. https://doi.org/10.1016/j.cell.2004.09.027.

(78) Mourkioti, F.; Kratsios, P.; Luedde, T.; Song, Y. H.; Delafontaine, P.; Adami, R.; Parente, V.; Bottinelli, R.; Pasparakis, M.; Rosenthal, N. Targeted Ablation of IKK2 Improves Skeletal Muscle 
Strength, Maintains Mass, and Promotes Regeneration. J. Clin. Invest. 2006, 116 (11), 2945-2954. https://doi.org/10.1172/JCI28721.

(79) Sartori, R.; Milan, G.; Patron, M.; Mammucari, C.; Blaauw, B.; Abraham, R.; Sandri, M. Smad2 and 3 Transcription Factors Control Muscle Mass in Adulthood. Am J Physiol Cell Physiol 2009, 296, 1248-1257. https://doi.org/10.1152/ajpcell.00104.2009.

(80) Goodman, C. A.; Hornberger, T. A. New Roles for Smad Signaling and Phosphatidic Acid in the Regulation of Skeletal Muscle Mass. F1000Prime Rep. 2014, 6 (April 2014), 20. https://doi.org/10.12703/P6-20.

(81) Trendelenburg, A. U.; Meyer, A.; Rohner, D.; Boyle, J.; Hatakeyama, S.; Glass, D. J. Myostatin Reduces Akt/TORC1/p70S6K Signaling, Inhibiting Myoblast Differentiation and Myotube Size. AJP Cell Physiol. 2009, 296 (6), C1258-C1270. https://doi.org/10.1152/ajpcell.00105.2009.

(82) Brunet, A.; Bonni, A.; Zigmond, M. J.; Lin, M. Z.; Juo, P.; Hu, L. S.; Anderson, M. J.; Arden, K. C.; Blenis, J.; Greenberg, M. E. Akt Promotes Cell Survival by Phosphorylating and Inhibiting a Forkhead Transcription Factor. Cell 1999, 96 (6), 857-868. https://doi.org/10.1016/S00928674(00)80595-4.

(83) Sandri, M.; Sandri, C.; Gilbert, A.; Skurk, C.; Calabria, E. Foxo Transcription Factors Induce the Atrophy- Related Ubiquitin Ligase Atrogin-1 and Cause Skeletal Muscle Atrophy. Cell 2004, 117, 12. https://doi.org/10.1016/j.jsbmb.2011.07.002.Identification.

(84) Rüegg, M. a; Glass, D. J. Molecular Mechanisms and Treatment Options for Muscle Wasting Diseases. Annu. Rev. Pharmacol. Toxicol. 2011, 51, 373-395. https://doi.org/10.1146/annurevpharmtox-010510-100537.

(85) Zhang, B.; Radisic, M. Organ-on-a-Chip Devices Advance to Market. Lab Chip 2017, 17 (14), 23952420. https://doi.org/10.1039/C6LC01554A. 
For Table of Contents Use Only:

Differentiation of bioengineered skeletal muscle within a 3D printed perfusion bioreactor reduces atrophic and inflammatory gene expression

Rowan P. Rimington, Andrew J. Capel, Kerry F. Chaplin, Jacob W. Fleming, H.C. Hemaka Bandulasena, Richard J. Bibb, Steven D. R. Christie, Mark P. Lewis.

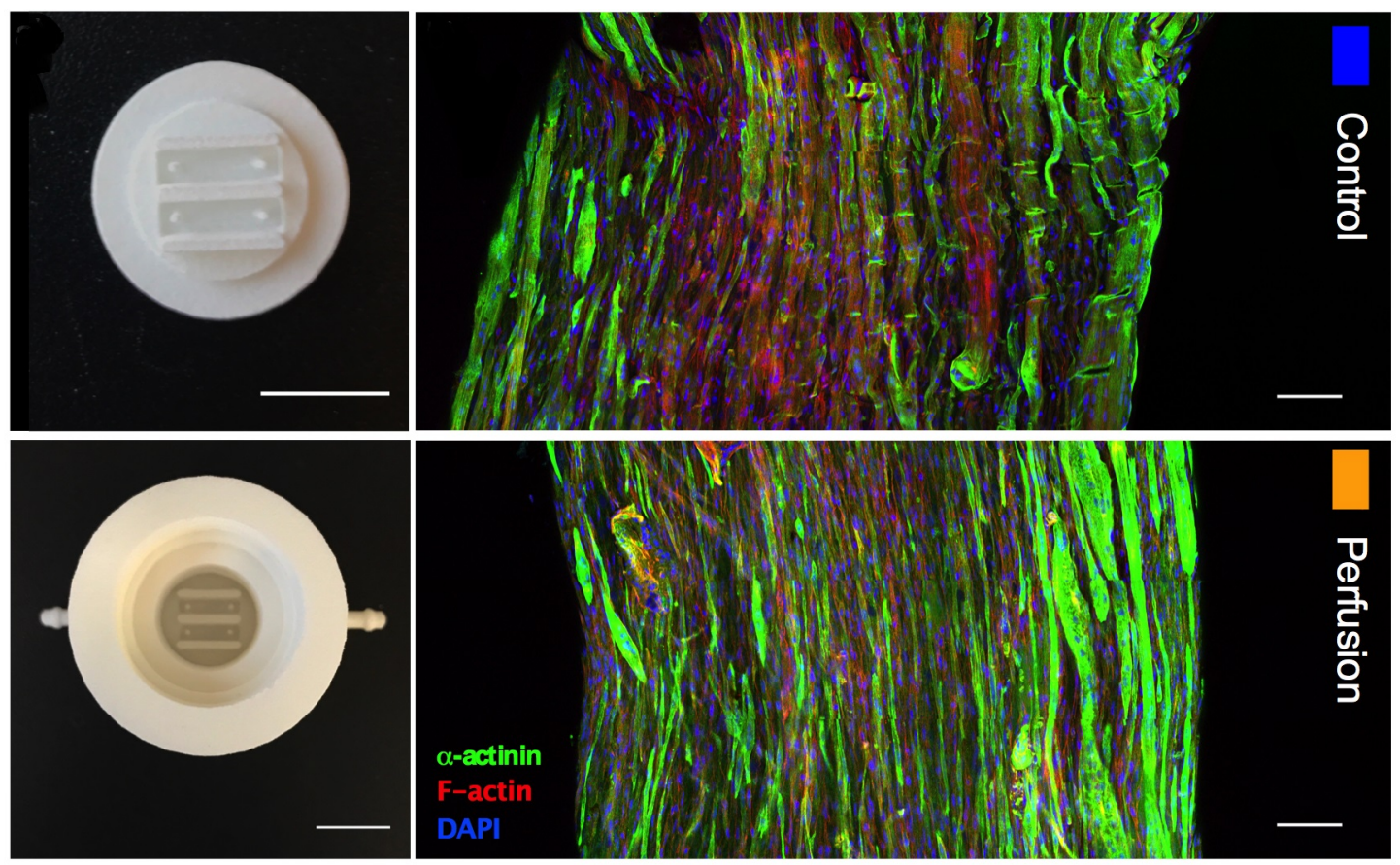

